Article

\title{
Efficient Multicomponent Synthesis of Diverse Antibacterial Embelin-Privileged Structure Conjugates
}

\author{
Pedro Martín-Acosta ${ }^{1}$, Rosalyn Peña ${ }^{1}$, Gabriela Feresin ${ }^{2}{ }^{\circledR}$, Alejandro Tapia ${ }^{2}$, \\ Isabel Lorenzo-Castrillejo ${ }^{3}$, Félix Machín ${ }^{3,4,5, *(D)}$, Ángel Amesty ${ }^{1, *}$ and Ana Estévez-Braun ${ }^{1, *(D)}$ \\ 1 Instituto Universitario de Bio-Orgánica Antonio González. Departamento de Química Orgánica. \\ Universidad de La Laguna Avda. Astrofísico Fco. Sánchez N² 2, 38206 La Laguna, Spain; \\ pmartina@ull.edu.es (P.M.-A.); rosalyn_pf@hotmail.com (R.P.) \\ 2 Instituto de Biotecnología-Instituto de Ciencias Básicas, Universidad Nacional de San Juan, Av. Libertador \\ General San Martín 1109 (O), CP 5400 San Juan, Argentina; gferesin@unsj.edu.ar (G.F.); \\ atapia@unsj.edu.ar (A.T.) \\ 3 Unidad de Investigación Hospital Universitario Nuestra Señora de La Candelaria, \\ 38010 Santa Cruz de Tenerife, Spain; belilorenzo2000@yahoo.es \\ 4 Instituto de Tecnologías Biomédicas, Universidad de la Laguna, 38200 Tenerife, Spain \\ 5 Facultad de Ciencias de la Salud, Universidad Fernando Pessoa Canarias, \\ 35450 Las Palmas de Gran Canaria, Spain \\ * Correspondence: fmachin@funcanis.es (F.M.); aarnesty@ull.edu.es (Á.A.); aestebra@ull.edu.es (A.E.-B.)
}

Academic Editor: Derek McPhee

Received: 30 June 2020; Accepted: 17 July 2020; Published: 20 July 2020

\begin{abstract}
A library of embelin derivatives has been synthesized through a multicomponent reaction from embelin (1), aldehydes and privileged structures such as 4-hydroxycoumarin, 4-hydroxy-2H-pyran-2-one and 2-naphthol, in the presence of $\mathrm{InCl}_{3}$ as catalyst. This multicomponent reaction implies Knoevenagel condensation, Michael addition, intramolecular cyclization and dehydration. Many of the synthesized compounds were active and selective against Gram-positive bacteria, including one important multiresistant Staphylococcus aureus clinical isolate. It was found how the conjugation of diverse privileged substructure with embelin led to adducts having enhanced antibacterial activities.
\end{abstract}

Keywords: embelin; multicomponent reactions; privileged structure; antimicrobial activity

\section{Introduction}

Natural products continue to play a pivotal role in the search for new therapeutic drug leads. They have inherent bioactivities and high bioavailability, probably because of their specific interactions with target macromolecules in living organisms. Thus, the chemical space defined by natural products may nicely overlap with biological space [1]. Therefore, structural motifs and core skeletons from bioactive natural products can serve for the synthesis of novel core skeletons with high biological relevancy. In this context, the natural benzoquinone embelin (1) is an attractive molecule since displays a good number of biological activities such as antimicrobial [2], inhibition of X-chromosome-linked inhibitor of apoptosis protein (XIAPS) [3], inhibition of mortalin-p53 interactions, and activation of p53 protein in tumor cells [4], inhibition of 5-lipoxygenase [5], antitumoral activity via activation of p38/JNK pathway [6] and antidiabetic activity [7].

Thus, this benzoquinone represents a good starting scaffold for the preparation of a structurally diverse collection of embelin derivatives. To assure the biological relevancy of this library we combine the use of privileged structures and complexity-generating reactions such 
as multicomponent reactions [8-12]. Privileged structures are defined as a single molecular framework able to provide a series of ligands for diverse receptors and have been extensively utilized in rational drug design owing to their potent biological activities [13]. Thus, from a domino Knoevenagel-Michael addition-cyclization-dehydration reaction using embelin (1), aldehydes and antibacterial privileged structural motifs as source of nucleophilic carbons, we can access to a library of dihydropyranbenzoquinones embedded with privileged substructures (Scheme 1). Moreover, this library may provide new compounds with great potency against both drug sensitive and drug-resistant Gram-positive and Gram-negative organisms.

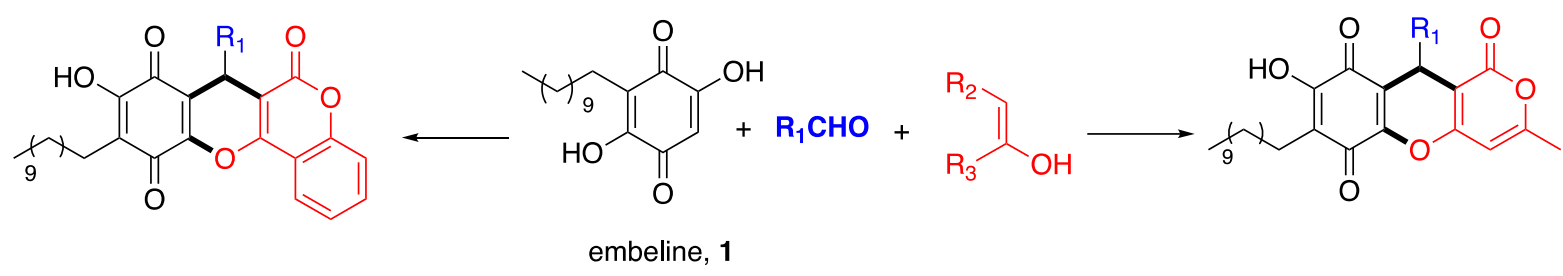

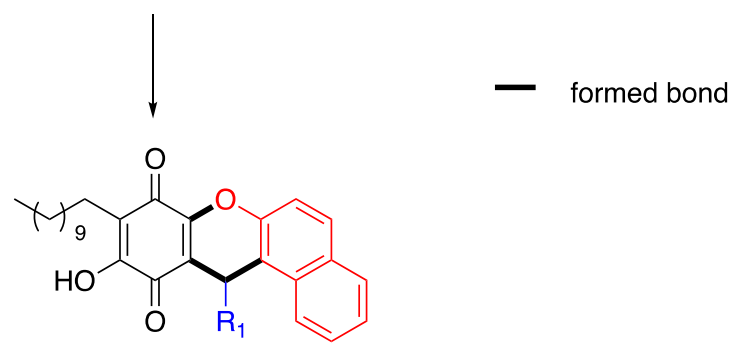

Scheme 1. Structure of embelin-privileged structure conjugates.

\section{Results and Discussion}

We selected the following molecular frameworks frequently observed in natural products and synthetic drugs with antibacterial activity [14,15]: 4-hydroxy-2H-pyran-2-one (2), 4-hydroxycoumarin (3), and 2-naphthol (4).

Since in the presence of an aldehyde both the embelin and the mentioned compounds (2-4) having nucleophilic carbons can react to afford the corresponding quinone methide intermediate via Knoevenagel condensation, we calculated the Fukui function in order to explore, which one shows the highest nucleophilicity. Fukui function is one of the widely used local density functional descriptor to model chemical reactivity and site-selectivity [16]. The local (condensed) Fukui functions $\left(f_{k}{ }^{+}, f_{k}{ }^{-}\right.$, $f_{k}{ }^{0}$ ) are calculated using the procedure proposed by Yang and Mortier [17], employing equations such as $f_{k}{ }^{+}=[\mathrm{q}(\mathrm{N}+1)-\mathrm{q}(\mathrm{N})]$ for nucleophilic attack; $f_{k}{ }^{-}=[\mathrm{q}(\mathrm{N})-\mathrm{q}(\mathrm{N}-1)]$ for electrophilic attack and $f_{k}{ }^{0}=\frac{1}{2}[\mathrm{q}(\mathrm{N}+1)-\mathrm{q}(\mathrm{N}-1)]$ for radical attack, where $\mathrm{N}$ is the total numbers of electrons. When a molecule accepts electrons, the electrons tend to go to places were $f_{k}{ }^{+}$is large because it is at these locations that the molecule is most able to stabilize additional electrons. Therefore a molecule is susceptible of an electrophilic attack at sites where $f_{k}{ }^{-}$is large. The calculated values of the Fukui function $\left(f_{\mathrm{k}}{ }^{-}\right)$are shown in Figure 1.

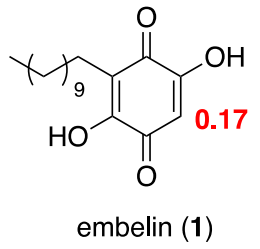<smiles>Cc1cc(O)cc(=O)o1</smiles><smiles></smiles><smiles>Oc1ccc2ccccc2c1O</smiles>

Figure 1. Location and highest value of the Fukui function $\left(f_{\mathrm{k}}-{ }^{-}\right)$for compounds (1-4). 
As we can see, compounds $\mathbf{2}-\mathbf{4}$ show higher values of $\left(\mathrm{f}^{-}\right)$than embelin $(\mathbf{1})$, which implies that the quinone methide intermediate is presumably formed from these compounds, and next the nucleophilic attack of embelin will take place on the more electrophilic $\alpha, \beta$-unsaturated carbonyl, followed of intramolecular cyclization with loss of $\mathrm{H}_{2} \mathrm{O}$ to yield the corresponding conjugates (Scheme 2).
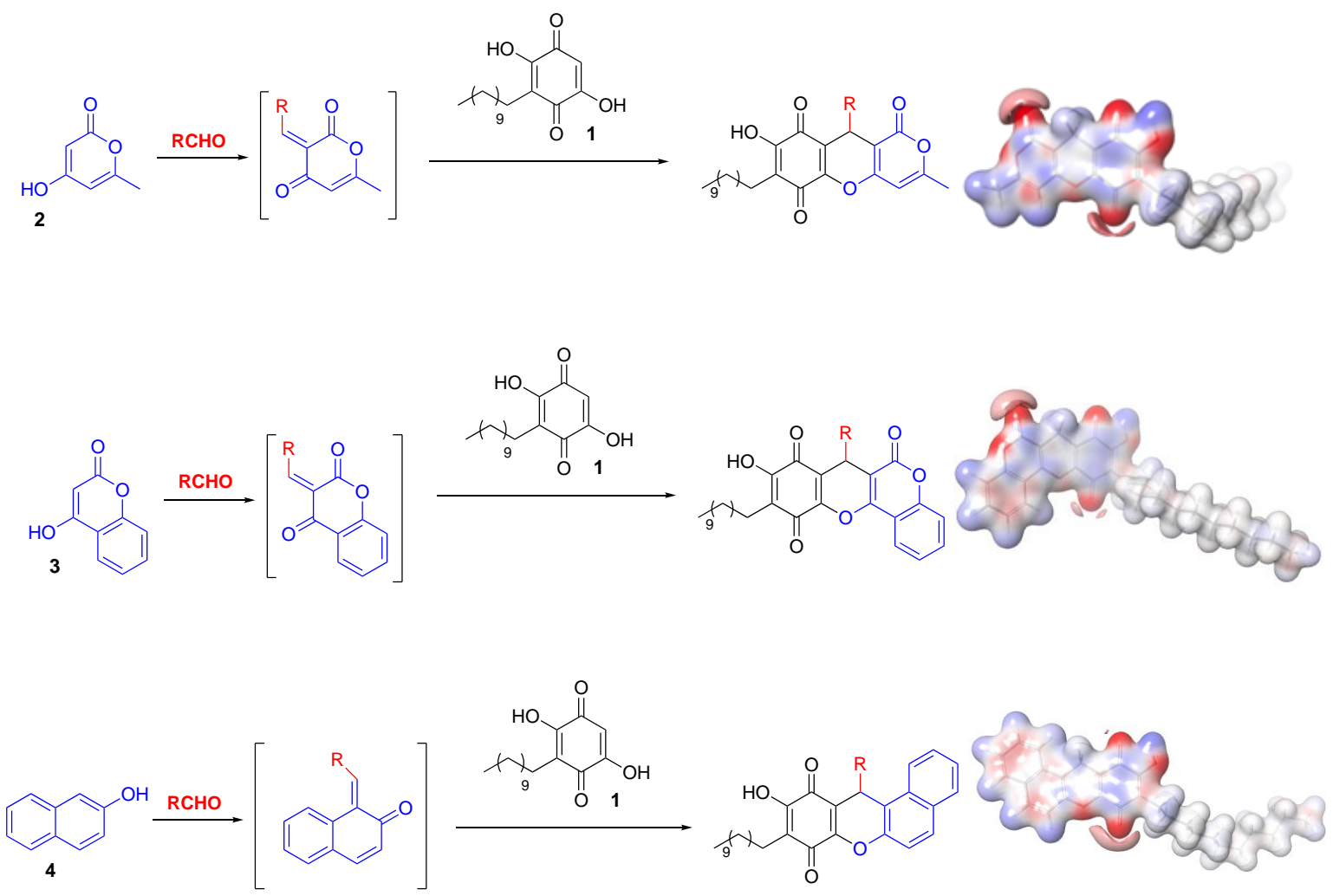

Scheme 2. Formation of embelin-conjugates.

Furthermore, for assessing the molecular diversity of the devised molecular framework, electrostatic polar surface area of energy-minimized conformers as well as the isosurface diagram of each adduct $(\mathrm{R}=\mathrm{H})$ were obtained by the calculation of electrostatic polar potentials and electron density [18]. As shown in Scheme 2, these three conjugates have a distinguishable display of electrostatic polar surface area because of the differentiation in electronic properties of each privileged substructure. The further expansion of molecular diversity can be achieved via the introduction of various moieties at the dihydropyran such as aliphatic and aromatic groups with electron donating and electron withdrawing substituents.

First, we decided to study the multicomponent reaction of embelin, 4-hydroxy-6-methyl2H-pyran-2-one (2) and 4-bromobenzaldehyde. We used different reaction conditions and several catalysts employed in multicomponent reactions of 1,3-dicarbonyl compounds such as EDDA [19], PTSA [20], Sc(OTf $)_{3}$ [21], $\mathrm{Yb}(\mathrm{OTf})_{3}$ [22], and $\mathrm{InCl}_{3}$ [23]. Some results are shown in Table 1. 
Table 1. Optimization of the MCR of 1, 2 and 4-bromobenzaldehyde.

\begin{tabular}{|c|c|c|}
\hline Entry & Conditions & Yield $(\%)$ * \\
\hline 1 & $10 \mathrm{~mol} \%$ EDDA, DCE, $\Delta, 24 \mathrm{~h}$ & - \\
\hline 2 & $10 \mathrm{~mol} \% \mathrm{EDDA}, \mathrm{EtOH}, \Delta, 24 \mathrm{~h}$ & - \\
\hline 3 & $\begin{array}{c}30 \mathrm{~mol} \% \text { EDDA, DCE, MW, } 120 \\
{ }^{\circ} \mathrm{C}, 30^{\prime}\end{array}$ & - \\
\hline 4 & $10 \mathrm{~mol}^{\circ} \mathrm{InCl}_{3}, \mathrm{EtOH}, \Delta, 3 \mathrm{~h}$ & 32 \\
\hline 5 & $10 \mathrm{~mol}^{\circ} \mathrm{InCl}_{3}$, neat, $120^{\circ} \mathrm{C}, 3 \mathrm{~h}$ & 52 \\
\hline 6 & $\begin{array}{c}10 \mathrm{~mol} \% \mathrm{Sc}(\mathrm{OTf})_{3}, \text { neat, } 120^{\circ} \mathrm{C}, 1.5 \\
\mathrm{~h}\end{array}$ & 32 \\
\hline 7 & $\begin{array}{c}10 \mathrm{~mol} \% \mathrm{Yb}(\mathrm{OTf})_{3}, \text { neat, } 120^{\circ} \mathrm{C}, \\
1.5 \mathrm{~h}\end{array}$ & 50 \\
\hline 8 & $10 \mathrm{~mol} \% \mathrm{PTSA}$, neat, $120^{\circ} \mathrm{C}, 1.5 \mathrm{~h}$ & 24 \\
\hline 9 & neat, $120^{\circ} \mathrm{C}, 3 \mathrm{~h}$ & 11 \\
\hline 10 & $20 \mathrm{~mol} \% \mathrm{InCl}_{3}$, neat, $120^{\circ} \mathrm{C}, 1.5 \mathrm{~h}$ & 58 \\
\hline 11 & $30 \mathrm{~mol} \% \mathrm{InCl}_{3}$, neat, $120^{\circ} \mathrm{C}, 1.5 \mathrm{~h}$ & 54 \\
\hline
\end{tabular}

The use of ethylendiamine diacetate (EDDA) as an effective organocatalyst for the initial Knoevenagel condensation did not produce the desired adduct $3 \mathbf{a}$ (entries 1-3). When $\mathrm{InCl}_{3}(10 \mathrm{~mol} \%)$ was used in EtOH under reflux compound 3a was obtained in low yield (32\%, entry 4). The yield was improved when the reaction was carried out without solvent $(52 \%$, entry 5$)$ at $120^{\circ} \mathrm{C}$. The use of other Lewis acids (entries 6 and 7) and $p$-toluenesulfonic acid (PTSA) (entry 8) under neat conditions at $120^{\circ} \mathrm{C}$, did not improved the yields. Increasing the load of $\mathrm{InCl}_{3}(20 \mathrm{~mol} \%)$ gave higher yield (58\%). We also carried out the multicomponent reaction without catalyst (entry 9) and adduct 3a was achieved in low yield (11\%). Thus, we selected the reaction conditions of entry 10 and the scope of this multicomponent process was then assessed through the variation of diverse aromatic and aliphatic aldehydes (Table 2). Diversely substituted tricyclic embelin adducts (3a-31) could be prepared in moderated yields, demonstrating the versatility of this domino process. As a general trend, the multicomponent reaction is tolerant to a large variety of aryl-substituted aldehydes with electron-donating and electron-withdrawing groups, and also the reaction proceeds with aliphatic aldehydes. 
Table 2. Synthesis of novel tricyclic embelin adducts (3a-31).

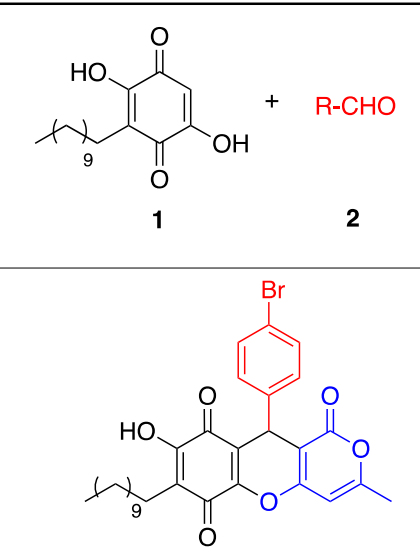

$3 a(58 \%)$

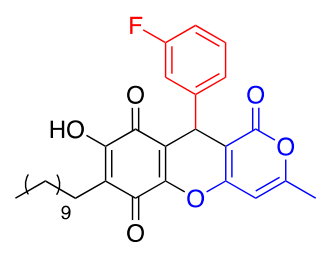

$3 d(48 \%)$<smiles>CCCCC1=C(O)C(=O)C2=C(Oc3cc(C)oc(=O)c3C2c2ccc(OC)c(OC)c2)C1=O</smiles>

$3 g(38 \%)$<smiles>CCCCCCC1C2=C(Oc3cc(C)oc(=O)c31)C(=O)C(CCCCC)=C(O)C2=O</smiles>

3j (38\%)<smiles>Cc1cc(O)cc(=O)o1</smiles>

3

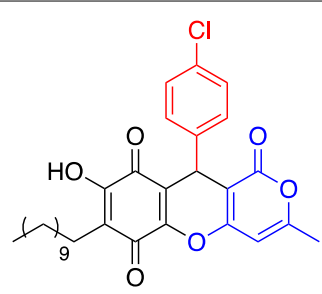

3b $(48 \%)$<smiles>CCCCCC1=C(O)C(=O)C2=C(Oc3cc(C)oc(=O)c3C2c2ccc([N+](=O)[O-])cc2)C1=O</smiles>

3e $(41 \%)$<smiles>CCCCCC1=C(O)C(=O)C2=C(Oc3cc(C)oc(=O)c3C2c2ccc3c(c2)OCO3)C1=O</smiles>

3h (34\%)<smiles>CCCCCC1=C(O)C(=O)C2=C(Oc3cc(C)oc(=O)c3C2CCC)C1=O</smiles>

3k (30\%)<smiles>[R]C1C(=O)C(=O)C(CC(C)C)=C(O)C1=O</smiles>

3a-3।

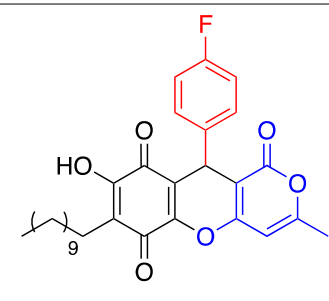

$3 c(42 \%)$<smiles>CCCCC1=C(O)C(=O)C2=C(Oc3cc(C)oc(=O)c3C2c2ccc(OC)c(F)c2)C1=O</smiles>

3f $(56 \%)$<smiles>CCCCCC1=C(O)C(=O)C2=C(Oc3cc(C)oc(=O)c3C2c2ccccc2)C1=O</smiles>

$3 \mathbf{i}(53 \%)$<smiles>CCCCCC1=C(O)C(=O)C2=C(Oc3cc(C)oc(=O)c3C2CC)C1=O</smiles>

3I $(25 \%)$

The reaction can be rationalized via the formation of a conjugated electron-deficient enone (A) through a Knoevenagel condensation of 2 and an aldehyde. The next step of this mechanism could involve a Michael addition of embelin (1) to the reactive quinone methide intermediate to yield the intermediate (B), which can undergo an intramolecular cyclization through carbonyl a to give the para-quinone adduct or through carbonyl $\mathbf{b}$ to yield the ortho-quinone adduct (Scheme 3). 


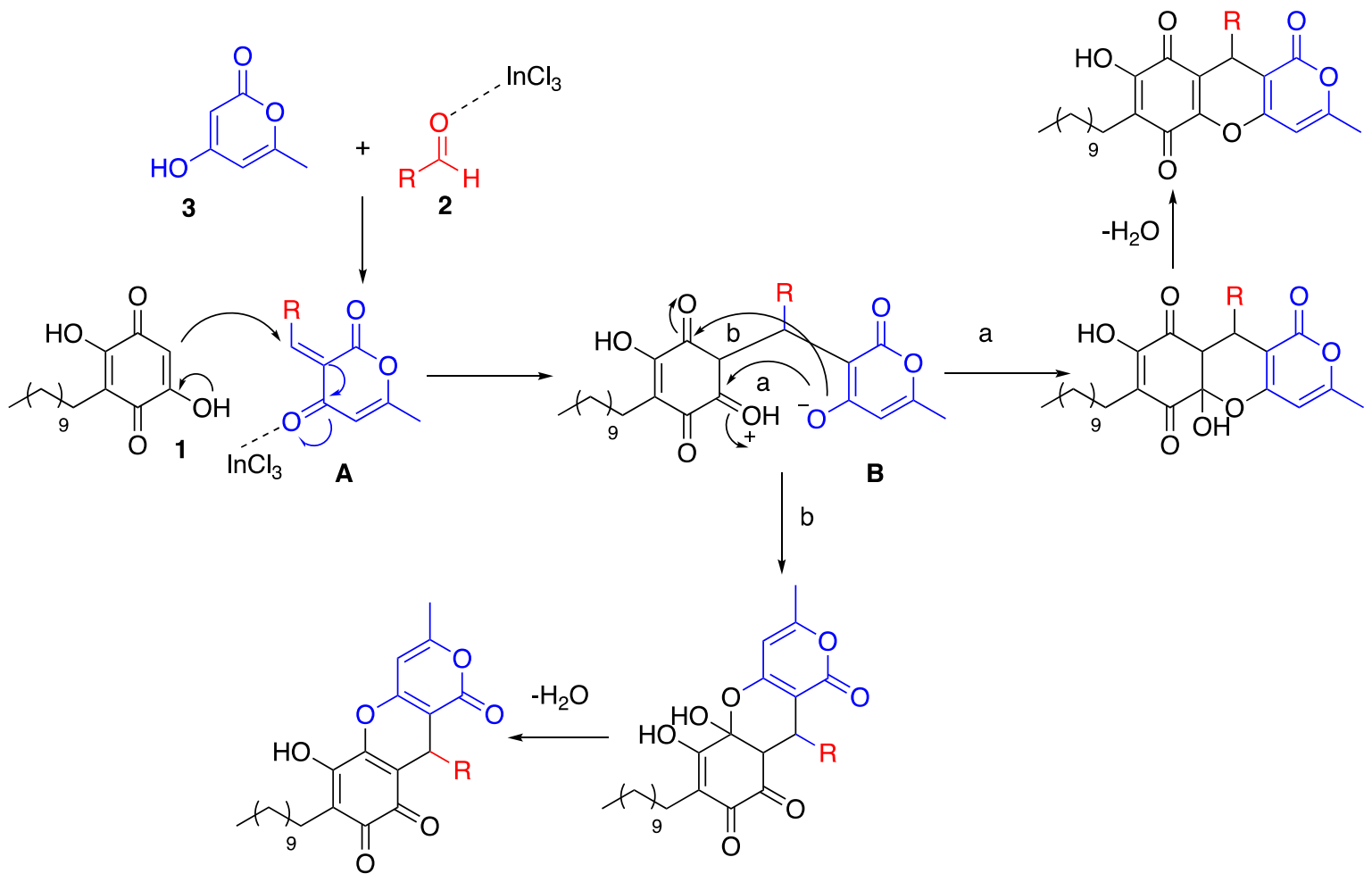

Scheme 3. Plausible formation of adducts $3 a-31$.

The process is regioselective since only the 1,4-benzoquinone adduct is obtained. A plausible explanation for this regioselectivity is that the reaction takes place through a more electron deficient carbonyl moiety next to another carbonyl group. Two new fused rings next to the benzoquinone core and three $\sigma$ bonds (two $\mathrm{C}-\mathrm{C} \sigma$ bonds and one $\mathrm{C}-\mathrm{O} \sigma$ bond) were formed in this multicomponent reaction. The regiosubstitution of the corresponding adducts was confirmed by the three-bond correlations detected in the HMBC spectrum and also by the ${ }^{13} \mathrm{C}$ NMR values of the quinone carbonyls [10-12] (Supplementary Materials). The $\mathrm{InCl}_{3}$ would promote the generation of the key quinone methide through dehydration of the alcohol formed in the Knoevenagel condensation and furthermore it could activate the quinone methide intermediates A.

Next, we decided to synthesize more complex embelin adducts by reacting embelin (1), aldehydes and the privileged structure 4-hydroxycoumarin (4). These tetracyclic adducts (4a-41) compared to adducts $3 \mathbf{a}-\mathbf{3 l}$ present an extension of the structure by the introduction of an aromatic ring fused to the $2 \mathrm{H}$-pyran-2-one nucleus, which results very attractive for the establishment of structure-activity relationships after biological evaluation. The same reaction conditions for the synthesis of adducts 3a-31 were used. Table 3 shows the structures and the yields of the obtained conjugates (4a-41). As we can see improved yields were achieved by using 4-hydroxycoumarin as nucleophile component in the initial Knoevenagel condensation. 
Table 3. Synthesis of novel embelin-coumarin conjugates (4a-4l).<smiles>CCCC1=C(O)C(=O)C=C(O)C1=O</smiles>

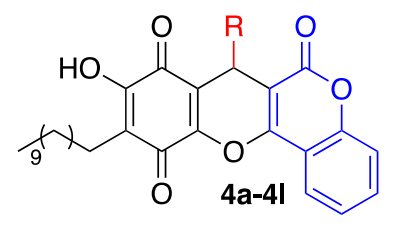<smiles></smiles>

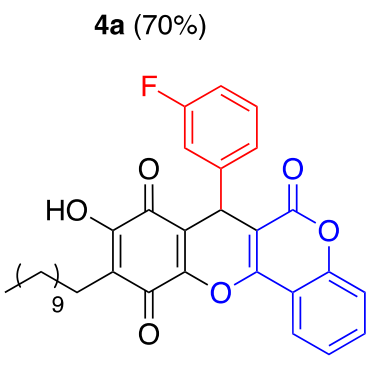

4d $(51 \%)$<smiles>CCCCCC1=C(O)C(=O)C(c2ccc(OC)c(COc3ccccc3)c2)C(=O)C1=O</smiles>

$4 \mathbf{g}(68 \%)$<smiles>CCCCCCC1C2=C(Oc3c1c(=O)oc1ccccc31)C(=O)C(CCCCC)=C(O)C2=O</smiles>

4j (68\%)<smiles></smiles>

4b (50\%)<smiles>CCCCCC1=C(O)C(=O)C2=C(Oc3c(c(=O)oc4ccccc34)C2c2ccc([N+](=O)[O-])cc2)C1=O</smiles>

4e $(64 \%)$<smiles>CCCCCC1=C(O)C(=O)C2=C(Oc3c(c(=O)oc4ccccc34)C2c2ccc3c(c2)OCO3)C1=O</smiles>

4h (59\%)<smiles>CCCCCCC1=C(O)C(=O)C2=C(Oc3c(c(=O)oc4ccccc34)C2CCC)C1=O</smiles>

4k (37\%)<smiles></smiles>

4c $(55 \%)$<smiles>CCCCCC1=C(O)C(=O)C2=C(Oc3c(c(=O)oc4ccccc34)C2c2ccc(OC)c(F)c2)C1=O</smiles>

$4 f(65 \%)$<smiles>CC(C)CC1C(=O)C(=O)C2=C(Oc3c(c(=O)oc4ccccc34)C2c2ccccc2)C1=O</smiles>

$4 \mathbf{i}(62 \%)$<smiles>CCC1C2=C(Oc3c1c(=O)oc1ccccc31)C(=O)C(O)=C(COCC(C)C)C2=O</smiles>

The last series was synthesized using 2-naphthol as nucleophilic component, in this case the tetracyclic adducts do not present the lactone ring of the previous series and they were obtained with higher yields than those from 4-hydroxy-2H-pyran-2-one and 4-hydroxycoumarin (Table 4). The conjugates synthesized from the aliphatic aldehydes $(5 \mathbf{j}-\mathbf{5 l})$ were achieved with the lowest yields. 
Table 4. Synthesis of novel tetracyclic embelin adducts (5a-5l).

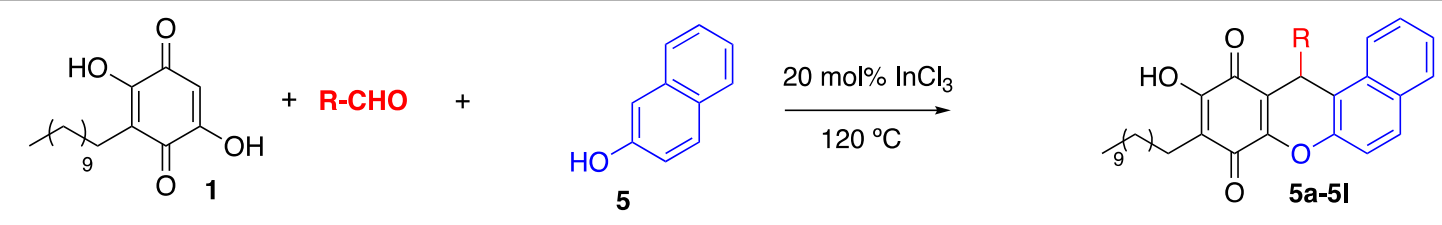<smiles>CC=CC1=C(O)C(=O)C2=C(C1=O)C(c1ccc(F)cc1)c1c(ccc3ccccc13)O2</smiles>

5a (65\%)<smiles>CCCCC1=C(O)C2=C(Oc3ccc4ccccc4c3C2c2ccc(OC)c(F)c2)C1=O</smiles>

5d (64\%)<smiles>CCCCCC1=C(O)C(=O)C2=C(C1=O)C(c1ccccc1)c1c(ccc3ccccc13)O2</smiles>

5g (83\%)<smiles>CCCCCCC1C(O)=C(CCCC)C(=O)c2oc3ccc4ccccc4c3c21</smiles>

5j (27\%)<smiles>CC(C)(C)C=CC1=C(O)C(=O)C(=O)C2=C1C(c1ccc(Cl)cc1)c1c(ccc3ccccc13)O2</smiles>

5b $(81 \%)$<smiles>CC(C)(C)C=CC1=C(O)C(=O)C(=O)C2=C1C(c1ccc([N+](=O)[O-])cc1)c1c(ccc3ccccc13)O2</smiles>

5e $(87 \%)$<smiles>O=c1c2c(c(=O)c(=O)c1=O)C(c1ccc3c(c1)OCO3)c1c(ccc3ccccc13)O2</smiles>

5h (88\%)<smiles>CCCC1C(O)=C(C=CC(C)(C)C)C(=O)c2oc3ccc4ccccc4c3c21</smiles><smiles>CC=CC1=C(O)C(=O)C2=C(C1=O)C(c1ccc(Br)cc1)c1c(ccc3ccccc13)O2</smiles>

$5 c(60 \%)$<smiles>CCCCCC1=C(O)C(=O)C2=C(Oc3ccc4ccccc4c3C2c2cccc(F)c2)C1=O</smiles>

$5 f(81 \%)$<smiles>CCCCC1=C(O)C(=O)C2=C(Oc3ccc4ccccc4c3C2c2ccc(OC)c(OC)c2)C1=O</smiles>

$5 i(82 \%)$<smiles>CCCCCC1=C(O)C(CC)c2c(oc3ccc4ccccc4c23)C1=O</smiles>

5I (48\%)

Since, the conjugation of embelin with other anti-bacterial moieties could provide new candidates with great potency against both drug sensitive and drug-resistant Gram-positive and Gram-negative organisms, all synthesized conjugates were tested for antimicrobial activity. The compounds had no effect on the growth of the assayed Gram-negative bacteria Escherichia coli and on the growth of the yeast Saccharomyces cerevisiae (MIC $>128 \mu \mathrm{M}$ ). By contrast, many compounds were selectively active against the three Gram-positive bacteria tested: the methicillin-sensitive Staphylococcus aureus (MSSA) ATCC25923 strain, the methicillin-resistant S. aureus NRS402 strain, which is also intermediate resistant 
to vancomycin (VISA), and the Enterococcus faecalis ATCC29212 strain (Table 5), and they were more active than embelin (1). This fact is interesting since bacterial infections, caused by Gram-positive pathogens such as Staphylococcus are account for the majority of opportunistic community-acquired and hospital-acquired infections.

Table 5. Minimum inhibitory concentration (MIC) for compounds $\mathbf{1}, \mathbf{3 a}-\mathbf{1}, \mathbf{4 a}-\mathbf{1}$, and $\mathbf{5 a}-\mathbf{1}$ against the three selected Gram-positive bacterial strains.

\begin{tabular}{|c|c|c|c|c|}
\hline Entry & Compound * & $\begin{array}{c}\text { S. aureus } \\
\text { (ATCC25923) }\end{array}$ & $\begin{array}{l}\text { S. aureus } \\
\text { (NRS402) }\end{array}$ & $\begin{array}{c}\text { E. faecalis } \\
\text { (ATCC29212) }\end{array}$ \\
\hline 1 & 1 & 32 & 32 & 128 \\
\hline 2 & $3 a$ & 1 & $<1$ & 2 \\
\hline 3 & $3 b$ & 2 & 2 & 1 \\
\hline 4 & $3 c$ & 2 & 2 & 1 \\
\hline 5 & $3 d$ & 2 & 2 & 2 \\
\hline 6 & $3 e$ & 4 & 4 & 2 \\
\hline 7 & $3 f$ & 2 & 2 & 2 \\
\hline 8 & $3 g$ & 2 & 4 & 4 \\
\hline 9 & $3 h$ & 4 & 4 & 2 \\
\hline 10 & $3 \mathbf{i}$ & 4 & 4 & 2 \\
\hline 11 & $3 \mathbf{j}$ & 8 & 4 & 2 \\
\hline 12 & $3 k$ & 4 & 4 & 4 \\
\hline 13 & 31 & 8 & 8 & 2 \\
\hline 14 & $4 a$ & 16 & 4 & 8 \\
\hline 15 & $4 b$ & 2 & 2 & 4 \\
\hline 16 & $4 c$ & 2 & 2 & 1 \\
\hline 17 & $4 d$ & 1 & 2 & 2 \\
\hline 18 & $4 e$ & 2 & 2 & 2 \\
\hline 19 & $4 \mathrm{f}$ & 8 & 2 & 4 \\
\hline 20 & $4 g$ & 1 & 2 & 2 \\
\hline 21 & $4 h$ & 2 & 2 & 4 \\
\hline 22 & $4 i$ & 4 & 2 & 2 \\
\hline 23 & $4 j$ & $>128$ & $>128$ & $>128$ \\
\hline 24 & $4 k$ & $>128$ & $>128$ & $>128$ \\
\hline 25 & 41 & 128 & 64 & 32 \\
\hline 26 & $5 a$ & $>128$ & $>128$ & $>128$ \\
\hline 27 & $5 b$ & $>128$ & $>128$ & $>128$ \\
\hline 28 & $5 c$ & $>128$ & 16 & 32 \\
\hline 29 & $5 d$ & $>128$ & 32 & 32 \\
\hline 30 & $5 e$ & $>128$ & $>128$ & $>128$ \\
\hline 31 & $5 f$ & $>128$ & $>128$ & $>128$ \\
\hline 32 & $5 \mathrm{~g}$ & $>128$ & 16 & 16 \\
\hline 33 & $5 \mathrm{~h}$ & $>128$ & $>128$ & $>128$ \\
\hline 34 & $5 i$ & $>128$ & 63 & 32 \\
\hline 35 & $5 \mathbf{j}$ & $>128$ & $>128$ & $>128$ \\
\hline 36 & $5 k$ & $>128$ & 32 & 32 \\
\hline 37 & 51 & $>128$ & 32 & 8 \\
\hline 38 & ampilicin & $<1$ & $>128$ & 8 \\
\hline 39 & oxacillin & $<1$ & $>128$ & 8 \\
\hline 40 & vancomycin & $<1$ & 4 & 4 \\
\hline 41 & mupirocin & $<1$ & $<1$ & 16 \\
\hline
\end{tabular}

${ }^{*}$ MICs for tested compounds are in $\mu \mathrm{M}$ and for reference antibiotics are in $\mathrm{mg} / \mathrm{L}$.

As we can see, the less active compounds turned out to be the conjugates with the naphthalene scaffold since most of them have MIC > $128 \mathrm{M}$ (entries 26-37). Thus, the presence of a $2 H$-pyran-2-one moiety seems to be important for the antibacterial activity. In the series from 4-hydroxy-2H-pyran-2-one good values were achieved with both aromatic and aliphatic substituents at the dihydropyran ring (entries 2-13). Embelin-coumarin conjugates with aliphatic substituents at the dihydropyran 
ring were inactive while those with aromatic substituents showed high activity. Regarding the influence of the nature of the substituents on the aromatic ring in the activity, in the series from 4-hydroxy-6-methyl-2H-pyran-2-one, halogen substituents in para position afforded the lowest MIC values (entries 2-4). In the embelin-coumarin series the best results were obtained with 4-fluorphenyl and 3,4-dimetoxyphenyl groups (entries 4 and 8).

\section{Materials and Methods}

\subsection{General Methods}

Commercial reagents were purchased from Sigma-Aldrich (Darmstadt, Germany) and Alfa Aesar (Lancashire, UK) and were used without further purification. Analytical thin-layer chromatography was performed on Polygram SIL G/UV254 silica gel plates and chromatograms were visualized under UV light (254 and $360 \mathrm{~nm}$ ). Pre-coated TLC plates SIL G-100 UV254 (Macherey-Nagel) and SILICA GEL GF plates (1000 $\mu \mathrm{m}$, Analtech) were used for preparative TLC purification. ${ }^{1} \mathrm{H}$ and ${ }^{13} \mathrm{C}$ NMR spectra were acquired in $\mathrm{CDCl}_{3}\left(0.03 \% v / v\right.$ TMS) DMSO- $d_{6}$ or $\mathrm{C}_{6} \mathrm{D}_{6}$ at room temperature using Bruker Avance instruments (Bruker, Billarica, MA, USA) (400 or $500 \mathrm{MHz}$ for ${ }^{1} \mathrm{H}$ NMR and 100 or $125 \mathrm{MHz}$ for ${ }^{13} \mathrm{C}$ NMR). Chemical shifts are reported in parts per million (ppm). For ${ }^{1} \mathrm{H}$ NMR data are reported in the following manner: Chemical shift (integration, multiplicity, coupling constant where applicable). The following abbreviations are used: $\mathrm{s}$ (singlet), br (broad), $\mathrm{d}$ (doublet), $\mathrm{t}$ (triplet), dd (double doublet), $\mathrm{td}$ (triplet of doublets), and $\mathrm{m}$ (multiplet). Coupling constants $(J)$ are given in Hertz $(\mathrm{Hz}) \cdot{ }^{13} \mathrm{C}$ NMR were obtained with complete proton decoupling. MS and HRMS data were recorded in a VG Micromass ZAB-2F spectrometer and an ESI instrument LCT Premier XE Micromass (ESI-TOF). IR spectra were recorded on a Bruker IFS 28/55 spectrophotometer. All compounds were named using the ACD40 Name-Pro program, which is based on IUPAC rules. The embelin (1) used in the reactions was obtained from Oxalis erythrorhiza Gillies ex Hook. \& Arn. following the procedure described in reference [24].

3.2. General Procedures for the Multicomponent Reaction between Embelin (1), Aldehyde (2), and 4-Hydroxy6-methyl-2-pyrone (3), with Indium Trichloride as Catalyst

Embelin (1) (20.0 mg, $0.068 \mathrm{mmol})$, the corresponding aldehyde (2) $(0.068 \mathrm{mmol})$, and 4-hydroxy6-methyl-2-pyrone (3) $(1.0 \mathrm{mmol})$ were grinded in a mortar for $5 \mathrm{~min}$. Then, $3.1 \mathrm{mg}$ of $\mathrm{InCl}_{3}(20 \mathrm{~mol} \%)$ was added and the reaction mixture was grinded again for $15 \mathrm{~min}$, placed in a sealed tube and kept in an oven at $120^{\circ} \mathrm{C}$ for $1.5 \mathrm{~h}$. The resulting crude was purified by preparative-TLC chromatography using hexanes: EtOAc (3:2) as eluant.

\subsection{0-4(4-Bromophenyl)-8-hydroxy-3-methyl-7undecylpyrano[4,3-b]chromene-1,6,9(10H)-trione (3a)}

Following the general procedure described above, $22.4 \mathrm{mg}(58 \%)$ of $3 \mathbf{a}$ were obtained as an amorphous violet solid. ${ }^{1} \mathrm{H}$ NMR $\left(400 \mathrm{MHz}, \mathrm{C}_{6} \mathrm{D}_{6}\right) \delta 0.91(3 \mathrm{H}, \mathrm{t}, J=6.2 \mathrm{~Hz}), 1.28(16 \mathrm{H}, \mathrm{bs}), 1.38(3 \mathrm{H}$, s), $1.60(2 \mathrm{H}, \mathrm{m}), 2.55(2 \mathrm{H}, \mathrm{t}, J=8.9 \mathrm{~Hz}), 4.78(1 \mathrm{H}, \mathrm{s}), 5.27(1 \mathrm{H}, \mathrm{s}), 7.09(2 \mathrm{H}, \mathrm{d}, J=8.2 \mathrm{~Hz}), 7.18(2 \mathrm{H}, \mathrm{d}$, $J=8.1 \mathrm{~Hz}) ;{ }^{13} \mathrm{C} \mathrm{NMR}\left(100 \mathrm{MHz}, \mathrm{CDCl}_{3}\right) \delta 14.1\left(\mathrm{CH}_{3}\right), 20.0\left(\mathrm{CH}_{3}\right), 22.7\left(\mathrm{CH}_{2}\right), 28.1\left(\mathrm{CH}_{2}\right), 29.3\left(\mathrm{CH}_{2}\right)$, $29.6\left(\mathrm{CH}_{2} \times 3\right), 29.7\left(\mathrm{CH}_{2} \times 2\right), 31.9\left(\mathrm{CH}_{2}\right), 32.9(\mathrm{CH}), 98.6(\mathrm{CH}), 101.9(\mathrm{C}), 117.5(\mathrm{C}), 120.0(\mathrm{C}), 121.9(\mathrm{C})$, 130.3 (CHx2), 131.7 (CHx2), 140.0 (C), 148.1 (C), 158.8 (C), 158.9 (C), 162.2 (C), 162.9 (C), 179.4 (C), 182.2 (C). EIMS m/z (\%): $568\left(\mathrm{M}^{+}, 0.93\right), 510(8), 509$ (16), 508 (34), 429 (23), 428 (17), 427 (24), 415 (17), 413 (96), $412\left(\mathrm{M}^{+}-\mathrm{C}_{6} \mathrm{H}_{4} \mathrm{Br}, 38\right), 368$ (8), 367 (15); HREIMS: 568.1483 (calcd for $\mathrm{C}_{30} \mathrm{H}_{33} \mathrm{O}_{6}{ }^{79} \mathrm{Br}\left(\mathrm{M}^{+}\right)$568.1461); 570.1445 (calcd for $\mathrm{C}_{30} \mathrm{H}_{33} \mathrm{O}_{6}{ }^{81} \mathrm{Br}\left(\mathrm{M}^{+}\right)$568.1441); IR $\left(\mathrm{CHCl}_{3}\right) v_{\max } 2923,1698,1651,1626,1594,1487$, $1383,1318,1211,1173,1125,1074,1037,993 \mathrm{~cm}^{-1}$.

\subsection{0-(4-Chlorophenyl)-8-hydroxy-3-methyl-7undecylpyrano[4,3-b]chromene-1,6,9(10H)-trione (3b)}

Following the general procedure described above, $17.1 \mathrm{mg}(48 \%)$ of $\mathbf{3 b}$ were obtained as an amorphous violet solid. ${ }^{1} \mathrm{H}$ NMR $\left(400 \mathrm{MHz}, \mathrm{C}_{6} \mathrm{D}_{6}\right) \delta 0.91(3 \mathrm{H}, \mathrm{t}, J=5.9 \mathrm{~Hz}), 1.28(16 \mathrm{H}, \mathrm{bs}), 1.38(3 \mathrm{H}, \mathrm{s})$, $1.60(2 \mathrm{H}, \mathrm{m}), 2.55(2 \mathrm{H}, \mathrm{t}, J=8.0 \mathrm{~Hz}), 4.80(1 \mathrm{H}, \mathrm{s}), 5.27(1 \mathrm{H}, \mathrm{s}), 6.65(1 \mathrm{H}, \mathrm{bs}), 7.02(2 \mathrm{H}, \mathrm{d}, J=8.3 \mathrm{~Hz}), 7.16$ 
$(2 \mathrm{H}, \mathrm{d}, J=8.6 \mathrm{~Hz}) ;{ }^{13} \mathrm{C} \mathrm{NMR}\left(100 \mathrm{MHz}, \mathrm{CDCl}_{3}\right) \delta 14.1\left(\mathrm{CH}_{3}\right), 20.1\left(\mathrm{CH}_{3}\right), 22.6\left(\mathrm{CH}_{2}\right), 22.7\left(\mathrm{CH}_{2}\right), 28.0$ $\left(\mathrm{CH}_{2}\right), 29.3\left(\mathrm{CH}_{2} \times 2\right), 29.5\left(\mathrm{CH}_{2}\right), 29.6\left(\mathrm{CH}_{2} \times 3\right), 31.9\left(\mathrm{CH}_{2}\right), 32.8(\mathrm{CH}), 98.4(\mathrm{CH}), 102.0(\mathrm{C}), 117.6(\mathrm{C})$, 119.9 (C), 128.8 (CHx2), 130.1 (CHx2), 133.7 (C), 139.5 (C), 147.8 (C), 151.1 (C), 158.6 (C), 161.9 (C), 162.9 (C), 179.4 (C), 181.5 (C); EIMS m/z (\%): $524\left(\mathrm{M}^{+}, 0.96\right), 415$ (22), $414(42), 413\left(\mathrm{M}^{+}-\mathrm{C}_{6} \mathrm{H}_{4} \mathrm{Cl}, 100\right), 412(42)$, 384 (30), 383 (44), 299 (11), 287 (16), 285 (36), 275 (22), 274 (79), 273 (45); HREIMS: 524.1931 (calcd for $\mathrm{C}_{30} \mathrm{H}_{33} \mathrm{O}_{6}{ }^{35} \mathrm{Cl}\left(\mathrm{M}^{+}\right)$524.1966), 526.1940 (calcd for $\mathrm{C}_{30} \mathrm{H}_{33} \mathrm{O}_{6}{ }^{37} \mathrm{Cl}\left(\mathrm{M}^{+}\right)$526.1936); IR $\left(\mathrm{CHCl}_{3}\right) v_{\max } 2923$, $1698,1626,1596,1318,1209,1125,1092,1038,992,973,807,653 \mathrm{~cm}^{-1}$.

\subsection{0-(4-Fluorophenyl)-8-hydroxy-3-methyl-7undecylpyrano[4,3-b]chromene-1,6,9(10H)-trione (3c)}

Following the general procedure described above, $14.5 \mathrm{mg}(42 \%)$ of $3 \mathrm{c}$ were obtained as an amorphous violet solid. ${ }^{1} \mathrm{H}$ NMR $\left(400 \mathrm{MHz}, \mathrm{CDCl}_{3}\right) \delta 0.91(3 \mathrm{H}, \mathrm{t}, J=5.7 \mathrm{~Hz}), 1.28(16 \mathrm{H}, \mathrm{bs}), 1.37(3 \mathrm{H}$, $\mathrm{s}), 1.58(2 \mathrm{H}, \mathrm{m}), 2.54(2 \mathrm{H}, \mathrm{t}, J=8.4 \mathrm{~Hz}), 4.84(1 \mathrm{H}, \mathrm{s}), 5.28(1 \mathrm{H}, \mathrm{s}), 6.71(2 \mathrm{H}, \mathrm{t}, J=8.0 \mathrm{~Hz}), 7.22(2 \mathrm{H}, \mathrm{m}) ;{ }^{13} \mathrm{C}$ $\operatorname{NMR}\left(100 \mathrm{MHz}, \mathrm{CDCl}_{3}\right) \delta 14.1\left(\mathrm{CH}_{3}\right), 20.1\left(\mathrm{CH}_{3}\right), 22.6\left(\mathrm{CH}_{2}\right), 22.7\left(\mathrm{CH}_{2}\right), 28.0\left(\mathrm{CH}_{2}\right), 29.3\left(\mathrm{CH}_{2} \times 2\right), 29.5$ $\left(\mathrm{CH}_{2}\right), 29.6\left(\mathrm{CH}_{2} \times 3\right), 31.9\left(\mathrm{CH}_{2}\right), 32.6(\mathrm{CH}), 98.4(\mathrm{CH}), 102.2(\mathrm{C}), 115.6\left(\mathrm{CHx} 2, J_{\mathrm{C}-\mathrm{F}}=21.4 \mathrm{~Hz}\right), 117.8(\mathrm{C})$, $119.9(\mathrm{C}), 130.3\left(\mathrm{CHx} 2, J_{\mathrm{C}-\mathrm{F}}=8.13 \mathrm{~Hz}\right), 136.8\left(\mathrm{C}, J_{\mathrm{C}-\mathrm{F}}=2.3 \mathrm{~Hz}\right), 147.7(\mathrm{C}), 151.0(\mathrm{C}), 158.5(\mathrm{C}), 161.9$ (C), $162.2\left(\mathrm{C}, J_{\mathrm{C}-\mathrm{F}}=245.8 \mathrm{~Hz}\right), 162.9(\mathrm{C}), 179.5(\mathrm{C}), 181.5(\mathrm{C})$; EIMS m/z (\%): $508\left(\mathrm{M}^{+}, 100\right), 415(5), 414$ $\left(\mathrm{M}^{+}-\mathrm{C}_{6} \mathrm{H}_{4} \mathrm{~F}, 26\right), 413$ (64), 412 (34), 368 15), 367 (35), 314 (27), 313 (12), 285 (26), 275 (12), 274 (53), 272 (26), 271 (25), 257 (15); HREIMS: 508.2251 (calcd. for $\mathrm{C}_{30} \mathrm{H}_{33} \mathrm{O}_{6} \mathrm{~F}\left(\mathrm{M}^{+}\right)$508.2261); $\mathrm{IR}\left(\mathrm{CHCl}_{3}\right) v_{\max }$ 2929, $2857,1701,1655,1629,1598,1511,1387,1322,1214,1175,1128,1042,998,837,817,747 \mathrm{~cm}^{-1}$.

\subsection{0-(3-Fluorophenyl)-8-Hydroxy-3-methyl-7undecylpyrano[4,3-b]chromene-1,6,9(10H)-trione (3d)}

Following the general procedure described above, $16.6 \mathrm{mg}(48 \%)$ of $\mathbf{3 d}$ were obtained as an amorphous violet solid. ${ }^{1} \mathrm{H}$ NMR $\left(400 \mathrm{MHz}, \mathrm{CDCl}_{3}\right) \delta: 0.87(3 \mathrm{H}, \mathrm{t}, J=6.4 \mathrm{~Hz}), 1.24(16 \mathrm{H}, \mathrm{bs}), 1.45(2 \mathrm{H}$, m), $2.26(3 \mathrm{H}), 2.44(2 \mathrm{H}, \mathrm{m}), 4.93(1 \mathrm{H}, \mathrm{s}), 6.19(1 \mathrm{H}, \mathrm{s}), 6.92(1 \mathrm{H}, \mathrm{m}), 7.03(1 \mathrm{H}, \mathrm{m}), 7.14(1 \mathrm{H}, \mathrm{m}), 7.25(1 \mathrm{H}, \mathrm{m})$; ${ }^{13} \mathrm{C} \mathrm{NMR}\left(100 \mathrm{MHz}, \mathrm{CDCl}_{3}\right) \delta 14.1\left(\mathrm{CH}_{3}\right), 20.1\left(\mathrm{CH}_{3}\right), 22.6\left(\mathrm{CH}_{2}\right), 22.7\left(\mathrm{CH}_{2}\right), 28.0\left(\mathrm{CH}_{2}\right), 29.3\left(\mathrm{CH}_{2} \times 2\right)$, $29.5\left(\mathrm{CH}_{2}\right), 29.6\left(\mathrm{CH}_{2} \times 3\right), 31.9\left(\mathrm{CH}_{2}\right), 33.0(\mathrm{CH}), 98.4(\mathrm{CH}), 101.9(\mathrm{C}), 114.8\left(\mathrm{CH}, J_{\mathrm{C}-\mathrm{F}}=21.1 \mathrm{~Hz}\right), 115.8$ $\left(\mathrm{CH}, J_{\mathrm{C}-\mathrm{F}}=21.9 \mathrm{~Hz}\right), 124.4\left(\mathrm{CH}, J_{\mathrm{C}-\mathrm{F}}=2.3 \mathrm{~Hz}\right), 130.1\left(\mathrm{CH}, J_{\mathrm{C}-\mathrm{F}}=8.2 \mathrm{~Hz}\right), 117.5(\mathrm{C}), 119.9(\mathrm{C}), 143.3(\mathrm{C}$, $\left.J_{\mathrm{C}-\mathrm{F}}=5.8 \mathrm{~Hz}\right), 147.9(\mathrm{C}), 151.1(\mathrm{C}), 158.7(\mathrm{C}), 161.9(\mathrm{C}), 162.9\left(\mathrm{C}, J_{\mathrm{C}-\mathrm{F}}=246.0 \mathrm{~Hz}\right), 163.0(\mathrm{C}), 179.4(\mathrm{C})$, 181.4 (C); EIMS m/z (\%): 508 (M+1 100$), 415$ (24), $414\left(\mathrm{M}^{+}-\mathrm{C}_{6} \mathrm{H}_{4} \mathrm{~F}, 33\right), 413$ (82), 369 (12), 368 (31), 367 (39), 285 (14), 274 (26); HREIMS: 508.2236 (calcd for $\mathrm{C}_{30} \mathrm{H}_{33} \mathrm{O}_{6} \mathrm{~F}\left(\mathrm{M}^{+}\right)$508.2261); IR $\left(\mathrm{CHCl}_{3}\right) v_{\max } 2926$, $2854,1699,1625,1623,1596,1446,1382,1318,1206,1122,1039,994,973,823 \mathrm{~cm}^{-1}$.

\subsection{0-(4-Nitrophenyl)-8-Hydroxy-3-methyl-7undecylpyrano[4,3-b]chromene-1,6,9(10H)-trione (3e)}

Following the general procedure described above, $14.9 \mathrm{mg}(41 \%)$ of $3 \mathbf{e}$ were obtained as an amorphous violet solid. ${ }^{1} \mathrm{H}$ NMR $\left(400 \mathrm{MHz}, \mathrm{C}_{6} \mathrm{D}_{6}\right) \delta: 0.91(3 \mathrm{H}, \mathrm{t}, J=5.6 \mathrm{~Hz}), 1.27(16 \mathrm{H}, \mathrm{bs}), 1.40(3 \mathrm{H}$, s), $1.62(2 \mathrm{H}, \mathrm{m}), 2.57(2 \mathrm{H}, \mathrm{bt}, J=9.2 \mathrm{~Hz}), 4.77(1 \mathrm{H}, \mathrm{s}), 5.27(1 \mathrm{H}, \mathrm{s}), 6.69(1 \mathrm{H}, \mathrm{s}), 7.11(2 \mathrm{H}, \mathrm{d}, J=7.8 \mathrm{~Hz})$, $7.72(2 \mathrm{H}, \mathrm{d}, J=7.7 \mathrm{~Hz}) ;{ }^{13} \mathrm{C}$ NMR $\left(100 \mathrm{MHz}, \mathrm{CDCl}_{3}\right) \delta 14.1\left(\mathrm{CH}_{3}\right), 20.2\left(\mathrm{CH}_{3}\right), 22.7\left(\mathrm{CH}_{2} \times 2\right), 28.0\left(\mathrm{CH}_{2}\right)$, $29.3\left(\mathrm{CH}_{2} \times 2\right), 29.5\left(\mathrm{CH}_{2}\right), 29.6\left(\mathrm{CH}_{2} \times 3\right), 31.9\left(\mathrm{CH}_{2}\right), 33.5(\mathrm{CH}), 98.4(\mathrm{CH}), 101.2(\mathrm{C}), 116.8(\mathrm{C}), 120.4$ (C), 123.9 (CHx2), 129.9 (CHx2), 147.1 (C), 147.8 (C), 148.2 (C), 151.2 (C), 158.9 (C), 161.7 (C), 163.6 (C), 179.1 (C), 181.4 (C); EIMS m/z (\%) $535\left(\mathrm{M}^{+}, 100\right), 415$ (15), $414(29), 413\left(\mathrm{M}^{+}-\mathrm{C}_{6} \mathrm{H}_{4} \mathrm{O}_{2} \mathrm{~N}, 78\right), 397(12)$, 396 (33), 395 (38), 382 (11), 324 (13), 285 (12), 274 (23), 273 (16), 271 (12); HREIMS: 535.2215 (calcd for $\mathrm{C}_{30} \mathrm{H}_{33} \mathrm{O}_{8} \mathrm{~N}\left(\mathrm{M}^{+}\right)$535.2206); IR $\left(\mathrm{CHCl}_{3}\right) v_{\max }: 2926,2855,2287,2166,1719,1626,1591,1518,1443,1382$, $1343,1326,1216,1171,1125,993,780 \mathrm{~cm}^{-1}$.

3.8. 10-(3-Fluoro-4-methoxyphenyl)-8-Hydroxy-3-methyl-7undecylpyrano[4,3-b]chromene-1,6,9(10H)trione (3f)

Following the general procedure described above, $20.5 \mathrm{mg}(56 \%)$ of $3 \mathrm{f}$ were obtained as an amorphous violet solid. ${ }^{1} \mathrm{H}$ NMR $\left(400 \mathrm{MHz}, \mathrm{C}_{6} \mathrm{D}_{6}\right) \delta: 0.91(3 \mathrm{H}, \mathrm{t}, J=5.4 \mathrm{~Hz}), 1.28(16 \mathrm{H}, \mathrm{bs}), 1.38(3 \mathrm{H}$, s), $1.58(2 \mathrm{H}, \mathrm{m}), 2.54(2 \mathrm{H}, \mathrm{t}, J=7.8 \mathrm{~Hz}), 3.17(3 \mathrm{H}, \mathrm{s}), 4.87(1 \mathrm{H}, \mathrm{s}), 5.27(1 \mathrm{H}, \mathrm{s}), 6.41(1 \mathrm{H}, \mathrm{t}, J=9.5 \mathrm{~Hz}), 7.16$ $(1 \mathrm{H}, \mathrm{s}), 7.24(1 \mathrm{H}, \mathrm{d}, J=10.4 \mathrm{~Hz}) ;{ }^{13} \mathrm{C} \mathrm{NMR}\left(100 \mathrm{MHz}, \mathrm{CDCl}_{3}\right) \delta 14.1\left(\mathrm{CH}_{3}\right), 20.1\left(\mathrm{CH}_{3}\right), 22.6\left(\mathrm{CH}_{2} \mathrm{x} 2\right)$, 
$28.1\left(\mathrm{CH}_{2}\right), 29.3\left(\mathrm{CH}_{2}\right), 29.4\left(\mathrm{CH}_{2}\right), 29.5\left(\mathrm{CH}_{2}\right), 29.6\left(\mathrm{CH}_{2} \times 3\right), 31.9\left(\mathrm{CH}_{2}\right), 32.3(\mathrm{CH}), 56.2\left(\mathrm{CH}_{3}\right), 98.5$ $(\mathrm{CH}), 102.1(\mathrm{C}), 113.3\left(\mathrm{CH}, J_{\mathrm{C}-\mathrm{F}}=0.8 \mathrm{~Hz}\right), 116.3\left(\mathrm{CH}, J_{\mathrm{C}-\mathrm{F}}=18.7 \mathrm{~Hz}\right), 117.5(\mathrm{C}), 119.9(\mathrm{C}), 124.6\left(\mathrm{CH}, J_{\mathrm{C}-\mathrm{F}}\right.$ $=8.6 \mathrm{~Hz}), 133.9(\mathrm{C}), 147.2\left(\mathrm{C}, J_{\mathrm{C}-\mathrm{F}}=9.7 \mathrm{~Hz}\right), 147.8(\mathrm{C}), 151.2(\mathrm{C}), 153.6(\mathrm{C}), 158.6(\mathrm{C}), 163.2\left(\mathrm{C}, J_{\mathrm{C}-\mathrm{F}}=\right.$ $247.6 \mathrm{~Hz}), 162.8(\mathrm{C}), 179.4(\mathrm{C}), 181.6(\mathrm{C}) ; \mathrm{EIMS} \mathrm{m} / \mathrm{z}(\%) 538\left(\mathrm{M}^{+}, 100\right), 415(4), 414(18), 413\left(\mathrm{M}^{+}-\mathrm{C}_{7} \mathrm{H}_{6} \mathrm{OF}\right.$, 21), 412 (14), 397 (33), 287 (17), 285 (18), 274 (30), 271 (13); HREIMS 538.2360 (calcd for $\mathrm{C}_{31} \mathrm{H}_{35} \mathrm{O}_{7} \mathrm{~F}\left(\mathrm{M}^{+}\right.$) 538.2367); IR $\left(\mathrm{CHCl}_{3}\right) v_{\max } 2927,2856,1705,1628,1600,1519,1446,1386,1323,1277,1216,1123,1034$, $998,817 \mathrm{~cm}^{-1}$.

\subsection{0-(3,4-Dimethoxyphenyl)-8-hydroxy-3-methyl-7undecylpyrano[4,3-b]chromene-1,6,9(10H)-trione (3g)}

Following the general procedure described above, $14.2 \mathrm{mg}(38 \%)$ of $3 \mathrm{~g}$ were obtained as an amorphous violet solid. ${ }^{1} \mathrm{H}$ NMR $\left(400 \mathrm{MHz}, \mathrm{CDCl}_{3}\right) \delta 0.91(3 \mathrm{H}, \mathrm{t}, J=6.3 \mathrm{~Hz}), 1.28(16 \mathrm{H}, \mathrm{bs}), 1.39(3 \mathrm{H}$, $\mathrm{s}), 1.60(2 \mathrm{H}, \mathrm{m}), 2.56(2 \mathrm{H}, \mathrm{t}, J=2.8 \mathrm{~Hz}), 3.30(3 \mathrm{H}, \mathrm{s}), 3.47(3 \mathrm{H}, \mathrm{s}), 4.96(1 \mathrm{H}, \mathrm{s}), 5.34(1 \mathrm{H}, \mathrm{s}), 6.48(1 \mathrm{H}, \mathrm{d}, J=$ $8.2 \mathrm{~Hz}), 6.80(1 \mathrm{H}, \mathrm{dd}, J=8.1,1.3 \mathrm{~Hz}), 7.27(1 \mathrm{H}, \mathrm{s}) ;{ }^{13} \mathrm{C} \mathrm{NMR}\left(100 \mathrm{MHz}, \mathrm{CDCl}_{3}\right) \delta 14.1\left(\mathrm{CH}_{3}\right), 20.1\left(\mathrm{CH}_{3}\right)$, 22.6 $\left(\mathrm{CH}_{2}\right), 22.7\left(\mathrm{CH}_{2}\right), 28.0\left(\mathrm{CH}_{2}\right), 29.3\left(\mathrm{CH}_{2}\right), 29.4\left(\mathrm{CH}_{2}\right), 29.5\left(\mathrm{CH}_{2}\right), 29.6\left(\mathrm{CH}_{2} \times 3\right), 31.9\left(\mathrm{CH}_{2}\right), 32.7$ $(\mathrm{CH}), 55.8\left(\mathrm{CH}_{3}\right), 56.1\left(\mathrm{CH}_{3}\right), 98.4(\mathrm{CH}), 102.5(\mathrm{C}), 111.2(\mathrm{CH}), 112.5(\mathrm{CH}), 118.1(\mathrm{C}), 119.7(\mathrm{C}), 120.5$ (CH), $133.7(\mathrm{C}), 147.6(\mathrm{C}), 148.7(\mathrm{C}), 148.9$ (C), $151.0(\mathrm{C}), 158.3$ (C), $162.1(\mathrm{C}), 162.5$ (C), 179.7 (C), 181.6 (C); $\operatorname{EIMS~m/z~(\% ):~} 550\left(\mathrm{M}^{+}, 100\right), 415$ (10), 414 (27), $413\left(\mathrm{M}^{+}-\mathrm{C}_{8} \mathrm{H}_{9} \mathrm{O}_{2}, 14\right), 410$ (21), 299 (11), 284 (12), 274 (36), 270 (10); HREIMS 550.2582 (calcd for $\mathrm{C}_{32} \mathrm{H}_{38} \mathrm{O}_{8}\left(\mathrm{M}^{+}\right)$550.2567); IR $\left(\mathrm{CHCl}_{3}\right) v_{\max } 2925$, 2854, $1726,1654,1625,15933,1514,1447,1325,1267,1217,1124,1027,993,823 \mathrm{~cm}^{-1}$.

3.10. 10-(Benzo[d][1,3]dioxo-5-yl)-8-hydroxy-3-methyl-7undecylpyrano[4,3-b]chromene-1,6,9(10H)-trione (3h)

Following the general procedure described above, $12.3 \mathrm{mg}(34 \%)$ of $3 \mathrm{~h}$ were obtained as an amorphous violet solid. ${ }^{1} \mathrm{H}$ NMR $\left(400 \mathrm{MHz}, \mathrm{C}_{6} \mathrm{D}_{6}\right) \delta 1.02(3 \mathrm{H}, \mathrm{t}, J=5.5 \mathrm{~Hz}), 1.39(16 \mathrm{H}, \mathrm{bs}), 1.47(3 \mathrm{H}, \mathrm{s})$, $1.67(2 \mathrm{H}, \mathrm{m}), 2.63(2 \mathrm{H}, \mathrm{bt}, J=7.4 \mathrm{~Hz}), 4.96(1 \mathrm{H}, \mathrm{s}), 5.29(2 \mathrm{H}, \mathrm{d}, J=11.6 \mathrm{~Hz}), 5.4(1 \mathrm{H}, \mathrm{s}), 6.70(1 \mathrm{H}, \mathrm{d}, J=$ $7.6 \mathrm{~Hz}), 6.91(1 \mathrm{H}, \mathrm{d}, J=7.6 \mathrm{~Hz}) ;{ }^{13} \mathrm{C}$ NMR $\left(100 \mathrm{MHz}, \mathrm{CDCl}_{3}\right) \delta 14.1\left(\mathrm{CH}_{3}\right), 20.0\left(\mathrm{CH}_{3}\right), 22.6\left(\mathrm{CH}_{2}\right), 22.7$ $\left(\mathrm{CH}_{2}\right), 28.1\left(\mathrm{CH}_{2}\right), 29.3\left(\mathrm{CH}_{2} \times 2\right), 29.4\left(\mathrm{CH}_{2}\right), 29.5\left(\mathrm{CH}_{2}\right), 29.6\left(\mathrm{CH}_{2} \times 2\right), 31.9\left(\mathrm{CH}_{2}\right), 32.8(\mathrm{CH}), 98.5(\mathrm{CH})$, 101.2 $\left(\mathrm{CH}_{2}\right), 102.4(\mathrm{C}), 108.3(\mathrm{CH}), 109.2(\mathrm{CH}), 122.2(\mathrm{CH}), 117.9(\mathrm{C}), 119.8(\mathrm{C}), 134.9(\mathrm{C}), 147.2(\mathrm{C}), 147.6$ (C), 147.9 (C), 151.2 (C), 158.4 (C), 162.0 (C), 162.6 (C), 179.6 (C), 181.8 (C); EIMS m/z (\%): $534\left(\mathrm{M}^{+}, 100\right)$, 415 (18), 414 (41), $413\left(\mathrm{M}^{+}-\mathrm{C}_{7} \mathrm{H}_{5} \mathrm{O}_{2}, 20\right), 412$ (24), 397 (4), 393 (36), 380 (4), 287 (12), 284 (19), 283 (15), 274 (60), 273 (16); HREIMS 534.2295 (calcd for $\mathrm{C}_{31} \mathrm{H}_{34} \mathrm{O}_{8}\left(\mathrm{M}^{+}\right)$534.2254); IR $\left(\mathrm{CHCl}_{3}\right) v_{\max }$ 2924, 2853, $1726,1624,1591,1486,1442,1325,1217,1125,1036,994,806,643 \mathrm{~cm}^{-1}$.

\subsection{8-Hydroxy-3-methyl-10-phenyl-7undecylpyrano[4,3-b]chromene-1,6,9(10H)-trione (3i)}

Following the general procedure described above, $17.6 \mathrm{mg}(53 \%)$ of $3 \mathbf{i}$ were obtained as an amorphous violet solid. ${ }^{1} \mathrm{H}$ NMR $\left(400 \mathrm{MHz}, \mathrm{CDCl}_{3}\right) \delta: 0.91(3 \mathrm{H}, \mathrm{t}, J=6.9 \mathrm{~Hz}), 1.28(16 \mathrm{H}, \mathrm{bs}), 1.35(3 \mathrm{H}$, s), $1.56(2 \mathrm{H}, \mathrm{m}), 2.52(2 \mathrm{H}, \mathrm{m}), 4.95(1 \mathrm{H}, \mathrm{s}), 5.28(1 \mathrm{H}, \mathrm{s}), 6.95(1 \mathrm{H}, \mathrm{m}), 7.07(2 \mathrm{H}, \mathrm{t}, J=7.0 \mathrm{~Hz}), 7.44(2 \mathrm{H}, \mathrm{d}$, $J=7.2 \mathrm{~Hz}) ;{ }^{13} \mathrm{C}$ NMR $\left(100 \mathrm{MHz}, \mathrm{CDCl}_{3}\right) \delta 14.1\left(\mathrm{CH}_{3}\right), 20.1\left(\mathrm{CH}_{3}\right), 22.6\left(\mathrm{CH}_{2}\right), 22.7\left(\mathrm{CH}_{2}\right), 28.1\left(\mathrm{CH}_{2}\right)$, $29.3\left(\mathrm{CH}_{2} \times 2\right), 29.4\left(\mathrm{CH}_{2}\right), 29.5\left(\mathrm{CH}_{2}\right), 29.6\left(\mathrm{CH}_{2} \times 2\right), 31.9\left(\mathrm{CH}_{2}\right), 33.2(\mathrm{CH}), 98.4(\mathrm{CH}), 102.4(\mathrm{C}), 118.0$ (C), $119.7(\mathrm{C}), 127.8(\mathrm{CH}), 128.7(\mathrm{CH}), 140.9(\mathrm{C}), 147.8(\mathrm{C}), 151.1(\mathrm{C}), 158.5(\mathrm{C}), 161.9(\mathrm{C}), 162.6(\mathrm{C}), 179.6$ (C), 181.6 (C); EIMS m/z (\%) $490\left(\mathrm{M}^{+}, 100\right), 415$ (13), 414 (24), $413\left(\mathrm{M}^{+}-\mathrm{C}_{6} \mathrm{H}_{5}, 74\right), 412$ (13), 351 (17), 350 (27), 349 (10), 285 (17), 274 (27), 273 (20), 271 (13), 270 (14); HREIMS 490.2346 (calcd para $\mathrm{C}_{30} \mathrm{H}_{34} \mathrm{O}_{6}$ $\left(\mathrm{M}^{+}\right)$490.2355); IR $\left(\mathrm{CHCl}_{3}\right) v_{\max } 2927,2856,1701,1655,1628,1599,1451,1386,1322,1211,1175,1127$, $1040,998,813,703 \mathrm{~cm}^{-1}$.

\subsection{0-Hexyl-8-hydroxy-3-methyl-7undecylpyrano[4,3-b]chromene-1,6,9(10H)-trione (3j)}

Following the general procedure described above, $8.6 \mathrm{mg}(20 \%)$ of $3 \mathbf{j}$ were obtained as an amorphous violet solid. ${ }^{1} \mathrm{H}$ NMR $\left(400 \mathrm{MHz}, \mathrm{C}_{6} \mathrm{D}_{6}\right) \delta 0.85(6 \mathrm{H}, \mathrm{m}), 1.01(2 \mathrm{H}, \mathrm{m}), 1.25(20 \mathrm{H}, \mathrm{bs}), 1.47$ $(2 \mathrm{H}, \mathrm{t}, J=7.0 \mathrm{~Hz}), 1.67(2 \mathrm{H}, \mathrm{m}), 1.85(2 \mathrm{H}, \mathrm{t}, J=8.8 \mathrm{~Hz}), 2.27(3 \mathrm{H}, \mathrm{s}), 2.46(2 \mathrm{H}, \mathrm{t}, J=6.9 \mathrm{~Hz}), 4.02(1 \mathrm{H}, \mathrm{t}$, $J=6.1 \mathrm{~Hz}), 6.09(1 \mathrm{H}, \mathrm{s}) ;{ }^{13} \mathrm{C}$ NMR $\left(100 \mathrm{MHz}, \mathrm{CDCl}_{3}\right) \delta 13.9\left(\mathrm{CH}_{3}\right), 14.1\left(\mathrm{CH}_{3}\right), 19.9\left(\mathrm{CH}_{3}\right), 22.6\left(\mathrm{CH}_{2}\right)$, 
22.7 $\left(\mathrm{CH}_{2}\right), 25.1\left(\mathrm{CH}_{2}\right), 27.4(\mathrm{CH}), 28.0\left(\mathrm{CH}_{2}\right), 29.2\left(\mathrm{CH}_{2}\right), 29.3\left(\mathrm{CH}_{2} \times 2\right), 29.4\left(\mathrm{CH}_{2} \times 2\right), 29.5\left(\mathrm{CH}_{2}\right), 29.6$ $\left(\mathrm{CH}_{2} \times 2\right), 31.7\left(\mathrm{CH}_{2}\right), 31.9\left(\mathrm{CH}_{2}\right), 32.4\left(\mathrm{CH}_{2}\right), 98.5(\mathrm{CH}), 101.6(\mathrm{C}), 118.2(\mathrm{C}), 119.6(\mathrm{C}), 149.5(\mathrm{C}), 151.5$ (C), 160.0 (C), 162.2 (C), 162.5 (C), 179.2 (C), 182.0 (C); EIMS m/z (\%) $498\left(\mathrm{M}^{+}, 0.10\right), 415$ (15), 414 (31), $413\left(\mathrm{M}^{+}-\mathrm{C}_{6} \mathrm{H}_{13}, 100\right), 385$ (6), 287 (4), 274 (11); HREIMS: 498.2990 (calcd. for $\mathrm{C}_{30} \mathrm{H}_{42} \mathrm{O}_{6}\left(\mathrm{M}^{+}\right)$498.2981); IR $\left(\mathrm{CHCl}_{3}\right) v_{\max } 2923,2854,1720,1623,1588,1443,1399,1330,1221,1116,1028,964,825,651 \mathrm{~cm}^{-1}$.

\subsection{8-Hydroxy-3-methyl-10-propyl-7undecylpyrano[4,3-b]chromene-1,6,9(10H)-trione (3k)}

Following the general procedure described above, $6.2 \mathrm{mg}(20 \%)$ of $3 \mathbf{k}$ were obtained as an amorphous violet solid. ${ }^{1} \mathrm{H}$ NMR $\left(400 \mathrm{MHz}, \mathrm{CDCl}_{3}\right) \delta: 0.87(6 \mathrm{H}, \mathrm{t}, J=6.0 \mathrm{~Hz}), 1.25(16 \mathrm{H}), 1.47(2 \mathrm{H}, \mathrm{m})$, $1.68(2 \mathrm{H}, \mathrm{m}), 1.82(2 \mathrm{H}, \mathrm{m}), 2.27(3 \mathrm{H}, \mathrm{s}), 2.45(2 \mathrm{H}, \mathrm{t}, J=6.7 \mathrm{~Hz}), 4.02(1 \mathrm{H}, \mathrm{bs}), 6.09(1 \mathrm{H}, \mathrm{s}) ;{ }^{13} \mathrm{C}$ NMR $\left(100 \mathrm{MHz}, \mathrm{CDCl}_{3}\right) \delta 13.9\left(\mathrm{CH}_{3}\right), 14.1\left(\mathrm{CH}_{3}\right), 18.4\left(\mathrm{CH}_{2}\right), 20.0\left(\mathrm{CH}_{3}\right), 22.6\left(\mathrm{CH}_{2}\right), 22.7\left(\mathrm{CH}_{2}\right), 27.4(\mathrm{CH})$, $28.1\left(\mathrm{CH}_{2}\right), 29.3\left(\mathrm{CH}_{2} \times 2\right), 29.6\left(\mathrm{CH}_{2} \times 4\right), 31.9\left(\mathrm{CH}_{2}\right), 34.7\left(\mathrm{CH}_{2}\right), 98.5(\mathrm{CH}), 101.7(\mathrm{C}), 118.2(\mathrm{C}), 128.8(\mathrm{C})$, 130.9 (C), 149.5 (C), 160.1 (C), 162.2 (C), 162.5 (C), 179.4 (C), 182.4 (C). EIMS m/z (\%): $456\left(\mathrm{M}^{+}, 0.03\right)$, 416 (3), 415 (15), 414 (21), $413\left(\mathrm{M}^{+}-\mathrm{C}_{3} \mathrm{H}_{7}, 100\right), 273$ (5). HREIMS 456.2517 (calcd. for $\mathrm{C}_{27} \mathrm{H}_{36} \mathrm{O}_{6}\left(\mathrm{M}^{+}\right)$ 456.2512); IR $\left(\mathrm{CHCl}_{3}\right) v_{\max } 2924,2854,1712,1624,1592,1445,1398,1330,1214,1168,1114,1036,969$, $812 \mathrm{~cm}^{-1}$.

\subsection{0-ethyl-8-Hydroxy-3-methyl-7undecylpyrano[4,3-b]chromene-1,6,9(10H)-trione (31)}

Following the general procedure described above, $7.5 \mathrm{mg}(25 \%)$ of 31 were obtained as an amorphous violet solid. ${ }^{1} \mathrm{H}$ NMR $\left(400 \mathrm{MHz}, \mathrm{CDCl}_{3}\right) \delta 0.74(3 \mathrm{H}, \mathrm{t}, J=7.5 \mathrm{~Hz}), 0.87(3 \mathrm{H}, \mathrm{t}, J=6.3 \mathrm{~Hz})$, $1.25(16 \mathrm{H}, \mathrm{bs}), 1.47(2 \mathrm{H}, \mathrm{t}, J=8.6 \mathrm{~Hz}), 1.75(1 \mathrm{H}, \mathrm{m}), 1.95(1 \mathrm{H}, \mathrm{m}), 2.27(3 \mathrm{H}, \mathrm{s}, \mathrm{Me}-3), 2.46(2 \mathrm{H}, \mathrm{t}$, $J=7.4 \mathrm{~Hz}), 4.04(1 \mathrm{H}, \mathrm{t}, J=4.3 \mathrm{~Hz}), 6.09(1 \mathrm{H}, \mathrm{s}), 7.13(1 \mathrm{H}, \mathrm{s}) ;{ }^{13} \mathrm{C} \mathrm{NMR}\left(100 \mathrm{MHz}, \mathrm{CDCl}_{3}\right) \delta 9.0\left(\mathrm{CH}_{3}\right)$, 14.1 $\left(\mathrm{CH}_{3}\right), 20.0\left(\mathrm{CH}_{3}\right), 22.6\left(\mathrm{CH}_{2}\right), 22.7\left(\mathrm{CH}_{2}\right), 24.8\left(\mathrm{CH}_{2}\right), 28.1\left(\mathrm{CH}_{2}\right), 28.2(\mathrm{CH}), 29.3\left(\mathrm{CH}_{2}\right), 29.4\left(\mathrm{CH}_{2}\right)$, $29.5\left(\mathrm{CH}_{2} \times 2\right), 29.6\left(\mathrm{CH}_{2} \times 2\right), 31.9\left(\mathrm{CH}_{2}\right), 98.5(\mathrm{CH}), 100.9(\mathrm{C}), 117.6(\mathrm{C}), 119.6(\mathrm{C}), 149.7(\mathrm{C}), 151.0(\mathrm{C})$, 160.2 (C), 162.3 (C), 162.5 (C), 179.4 (C), 182.4 (C); EIMS m/z (\%) $442\left(\mathrm{M}^{+}, 1\right), 416$ (5), 415 (14), 414 (33), $413\left(\mathrm{M}^{+}-\mathrm{C}_{2} \mathrm{H}_{5}, 100\right), 385$ (4), 287 (4), 275 (5), 274 (12); HREIMS: 442.2349 (calcd for $\mathrm{C}_{26} \mathrm{H}_{34} \mathrm{O}_{6}\left(\mathrm{M}^{+}\right.$) 442.2355); IR $\left(\mathrm{CHCl}_{3}\right) v_{\max } 2924,2854,1721,1623,1587,1446,1399,1324,1260,1219,1160,1111,1018$, $984,824 \mathrm{~cm}^{-1}$.

\subsection{General Procedures for the Multicomponent Reaction between Embelin (1), Aldehyde (2), And} 4-Hydroxycoumarin (4), With Indium Trichloride as Catalyst

Embelin (1) $(20.0 \mathrm{mg}, 0.068 \mathrm{mmol})$, the corresponding aldehyde (2) $(0.068 \mathrm{mmol})$, and 4-hydroxycoumarin (4) $(1.0 \mathrm{mmol})$ were grinded in a mortar for $5 \mathrm{~min}$. Then, $3.1 \mathrm{mg}$ of $\mathrm{InCl}_{3}$ (20 $\mathrm{mol} \%$ ) was added and the reaction mixture was grinded again for $15 \mathrm{~min}$, placed in a sealed tube and kept in an oven at $120^{\circ} \mathrm{C}$ for $1.5 \mathrm{~h}$. The resulting crude was purified by preparative-TLC chromatography using toluene: EtOAc (9:1) as eluant.

\subsection{7-(4-Bromophenyl)-9-hydroxy-10-undecylchromeno[4,3-b]chromene-6,8,11(7H)-trione (4a)}

Following the general procedure described above, $28.7 \mathrm{mg}(70 \%)$ of 4 a were obtained as an amorphous violet solid. ${ }^{1} \mathrm{H}$ NMR $\left(400 \mathrm{MHz}, \mathrm{C}_{6} \mathrm{D}_{6}\right) \delta 1.11(3 \mathrm{H}, \mathrm{t}, J=4.7 \mathrm{~Hz}), 1.44(16 \mathrm{H}, \mathrm{bs}), 1.83(2 \mathrm{H}, \mathrm{t}$, $J=7.4 \mathrm{~Hz}), 2.77(2 \mathrm{H}, \mathrm{d}, J=4.6 \mathrm{~Hz}), 5.1(1 \mathrm{H}, \mathrm{s}), 6.83(1 \mathrm{H}, \mathrm{s}), 6.99(1 \mathrm{H}, \mathrm{t}, J=7.5 \mathrm{~Hz}), 7.04(2 \mathrm{H}, \mathrm{d}, J=$ $8.2 \mathrm{~Hz}), 7.10(1 \mathrm{H}, \mathrm{t}, J=6.9 \mathrm{~Hz}), 7.25(2 \mathrm{H}, \mathrm{d}, J=7.8 \mathrm{~Hz}), 8.17(2 \mathrm{H}, \mathrm{d}, J=7.5 \mathrm{~Hz}) ;{ }^{13} \mathrm{C}$ NMR $(100 \mathrm{MHz}$, $\left.\mathrm{CDCl}_{3}\right)$ \& $14.1\left(\mathrm{CH}_{3}\right), 22.7\left(\mathrm{CH}_{3} \times 2\right), 28.1\left(\mathrm{CH}_{2}, \mathrm{C}-15\right), 29.3\left(\mathrm{CH}_{2} \times 2\right), 29.4\left(\mathrm{CH}_{2}\right), 29.5\left(\mathrm{CH}_{2}\right), 29.7\left(\mathrm{CH}_{2} \times 2\right)$, $31.9\left(\mathrm{CH}_{2}\right), 33.5(\mathrm{CH}), 104.7(\mathrm{C}), 113.2(\mathrm{C}), 116.9(\mathrm{CH}), 117.5(\mathrm{C}), 120.2(\mathrm{C}), 122.1(\mathrm{C}), 123.4(\mathrm{CH}), 124.9$ (CH), 130.7 (CH x2), 131.9 (CHx2), $133.2(\mathrm{CH}), 139.5$ (C), 147.6 (C), $151.2(\mathrm{C}), 152.7$ (C), $154.4(\mathrm{C}), 160.3$ (C), 179.4 (C), 181.7 (C); EIMS m/z (\%) $606\left(\mathrm{M}^{+}, 100\right), 604\left(\mathrm{M}^{+}, 90\right), 466$ (21), 464 (28), 451 (11), 448 (35), 321 (35); HREIMS: 606.1441 (calcd for $\mathrm{C}_{33} \mathrm{H}_{33} \mathrm{O}_{6}{ }^{81} \mathrm{Br}\left(\mathrm{M}^{+}\right.$) 606.1440), 604.1458 (calcd for $\mathrm{C}_{33} \mathrm{H}_{33} \mathrm{O}_{6}{ }^{79} \mathrm{Br}$ $\left(\mathrm{M}^{+}\right)$606.1461); IR $\left(\mathrm{CHCl}_{3}\right) v_{\max } 3343,2923,2852,1719,1639,1609,1527,1490,1457,1378,1332,1289$, $1182 \mathrm{~cm}^{-1}$. 


\subsection{7-(4-Chlorophenyl)-9-hydroxy-10-undecylchromeno[4,3-b]chromene-6,8,11(7H)-trione (4b)}

Following the general procedure described above, $19.0 \mathrm{mg}(50 \%)$ of $4 \mathbf{b}$ were obtained as an amorphous violet solid. ${ }^{1} \mathrm{H}$ NMR $\left(400 \mathrm{MHz}, \mathrm{C}_{6} \mathrm{D}_{6}\right) \delta 1.11(3 \mathrm{H}, \mathrm{t}, J=5.5 \mathrm{~Hz}), 1.49(16 \mathrm{H}, \mathrm{bs}), 1.83$ $(2 \mathrm{H}, \mathrm{t}, J=8.1 \mathrm{~Hz}), 2.77(2 \mathrm{H}, \mathrm{d}, J=4.4 \mathrm{~Hz}), 5.1(1 \mathrm{H}, \mathrm{s}), 6.81(1 \mathrm{H}, \mathrm{s}), 6.99(1 \mathrm{H}, \mathrm{t}, J=7.1 \mathrm{~Hz}), 7.04(1 \mathrm{H}$, $\mathrm{d}, J=8.0 \mathrm{~Hz}), 7.10(1 \mathrm{H}, \mathrm{t}, J=7.6 \mathrm{~Hz}), 7.19(2 \mathrm{H}, \mathrm{d}, J=7.8 \mathrm{~Hz}), 7.32(2 \mathrm{H}, \mathrm{d}, J=7.9 \mathrm{~Hz}), 8.17(1 \mathrm{H}, \mathrm{d}$, $J=7.8 \mathrm{~Hz}) ;{ }^{13} \mathrm{C} \mathrm{NMR}\left(150 \mathrm{MHz},\left(\mathrm{CD}_{3}\right)_{2} \mathrm{SO}\right) \delta 14.4\left(\mathrm{CH}_{3}\right), 22.5\left(\mathrm{CH}_{2}\right), 22.8\left(\mathrm{CH}_{2}\right), 28.5\left(\mathrm{CH}_{2}\right), 29.2\left(\mathrm{CH}_{2}\right)$, $29.5\left(\mathrm{CH}_{2} \times 2\right), 29.5\left(\mathrm{CH}_{2} \times 2\right), 29.7\left(\mathrm{CH}_{2}\right), 31.7\left(\mathrm{CH}_{2}\right), 33.6(\mathrm{CH}), 104.9(\mathrm{C}), 113.7(\mathrm{C}), 115.9(\mathrm{C}), 116.9(\mathrm{CH})$, 117.1 (C), $123.1(\mathrm{CH}), 125.4(\mathrm{CH}), 128.6(\mathrm{CHx} 2), 131.1(\mathrm{CHx} 2), 132.2(\mathrm{CH}), 133.5(\mathrm{C}), 141.4(\mathrm{C}), 148.6(\mathrm{C})$, 148.7 (C), 152.4 (C), 154.4 (C), 160.3 (C), 176.4 (C), 184.1 (C); EIMS m/z (\%) $560\left(\mathrm{M}^{+}, 100\right), 562\left(\mathrm{M}^{+}, 41\right)$,

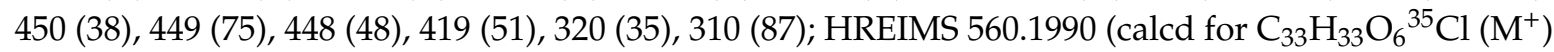
560.1966), 562.1977 (calcd for $\mathrm{C}_{33} \mathrm{H}_{33} \mathrm{O}_{6}{ }^{37} \mathrm{Cl}\left(\mathrm{M}^{+}\right)$562.1936); IR $\left(\mathrm{CHCl}_{3}\right) v_{\max } 3338,2925,2854,1719$, $1640,1611,1492,1458,1395,1335,1291,1231,1182,1046 \mathrm{~cm}^{-1}$.

\subsection{7-(4-Fluorophenyl)-9-hydroxy-10-undecylchromeno[4,3-b]chromene-6,8,11(7H)-trione (4c)}

Following the general procedure described above, $20.3 \mathrm{mg}(55 \%)$ of $4 \mathrm{c}$ were obtained as an amorphous violet solid ${ }^{1} \mathrm{H}$ NMR $\left(400 \mathrm{MHz}, \mathrm{C}_{6} \mathrm{D}_{6}\right) \delta 1.11(3 \mathrm{H}, \mathrm{t}, J=5.4 \mathrm{~Hz}), 1.48(16 \mathrm{H}, \mathrm{bs}), 1.82(2 \mathrm{H}, \mathrm{t}$, $J=7.1 \mathrm{~Hz}), 2.77(2 \mathrm{H}, \mathrm{d}, J=6.6 \mathrm{~Hz}), 5.13(1 \mathrm{H}, \mathrm{s}), 6.89(2 \mathrm{H}, \mathrm{t}, J=8.0 \mathrm{~Hz}), 7.01(4 \mathrm{H}, \mathrm{m}, J=8.4,5.5 \mathrm{~Hz}), 7.09$ $(1 \mathrm{H}, \mathrm{d}, J=7.5 \mathrm{~Hz}), 8.18(1 \mathrm{H}, \mathrm{d}, J=7.5 \mathrm{~Hz}),{ }^{13} \mathrm{C} \mathrm{NMR}\left(100 \mathrm{MHz}, \mathrm{CDCl}_{3}\right) \delta: 14.1\left(\mathrm{CH}_{3}\right), 22.7\left(\mathrm{CH}_{2} \times 2\right)$, $28.1\left(\mathrm{CH}_{2}\right), 29.3\left(\mathrm{CH}_{2}\right), 29.4\left(\mathrm{CH}_{2}\right), 29.5\left(\mathrm{CH}_{2}\right), 29.6\left(\mathrm{CH}_{2}\right), 29.7\left(\mathrm{CH}_{2} \times 2\right), 31.9\left(\mathrm{CH}_{2}\right), 33.2(\mathrm{CH}), 104.9$ (C), $113.2(\mathrm{C}), 115.7\left(\mathrm{CH}, J_{\mathrm{C}-\mathrm{F}}=21.7 \mathrm{~Hz}\right), 116.9(\mathrm{CH}), 117.7(\mathrm{C}), 120.0(\mathrm{C}), 123.2(\mathrm{CH}), 124.8(\mathrm{CH}), 128.9$ (C), $130.5\left(\mathrm{CH}, J_{\mathrm{C}-\mathrm{F}}=8.3 \mathrm{~Hz}\right), 133.0(\mathrm{CH}), 136.6(\mathrm{C}), 147.6(\mathrm{C}), 152.6(\mathrm{C}), 154.3(\mathrm{C}), 160.2(\mathrm{C}), 162.2(\mathrm{C}$, $\left.J_{\mathrm{C}-\mathrm{F}}=246.1 \mathrm{~Hz}\right), 179.4(\mathrm{C}), 181.7(\mathrm{C})$; EIMS m/z (\%) $544\left(\mathrm{M}^{+}, 68\right), 449$ (81), 404 (30), 307 (39), 309 (100), 337 (39), 295 (11); HREIMS 544.2274 (calcd for $\mathrm{C}_{33} \mathrm{H}_{33} \mathrm{O}_{6} \mathrm{~F}\left(\mathrm{M}^{+}\right)$544.2261); IR ( $\left.\mathrm{CHCl}_{3}\right) v_{\max }$ 2924, 2853, $1712,1636,1609,1561,1508,1458,1329,1294,1230,1186,1050 \mathrm{~cm}^{-1}$.

\subsection{7-(3-Fluorophenyl)-9-hydroxy-10-undecylchromeno[4,3-b]chromene-6,8,11(7H)-trione (4d)}

Following the general procedure described above, $18.9 \mathrm{mg}(51 \%)$ of $4 \mathbf{d}$ were obtained as an amorphous violet solid. ${ }^{1} \mathrm{H}$ NMR $\left(500 \mathrm{MHz}, \mathrm{C}_{6} \mathrm{D}_{6}\right) \delta: 1.11(3 \mathrm{H}, \mathrm{t}, J=6.6 \mathrm{~Hz}), 1.49(16 \mathrm{H}, \mathrm{bs}), 1.79(2 \mathrm{H}, \mathrm{t}$, $J=6.9 \mathrm{~Hz}), 2.74(2 \mathrm{H}, \mathrm{m}), 5.16(1 \mathrm{H}, \mathrm{s}), 6.82(1 \mathrm{H}, \mathrm{t}, J=7.6 \mathrm{~Hz}), 6.97(1 \mathrm{H}, \mathrm{t}, J=7.6 \mathrm{~Hz}), 7.02(2 \mathrm{H}, \mathrm{d}, J=8.6$ $\mathrm{Hz}), 7.06(1 \mathrm{H}, \mathrm{t}, J=8.1 \mathrm{~Hz}), 7.27(1 \mathrm{H}, \mathrm{d}, J=7.7 \mathrm{~Hz}), 7.51(1 \mathrm{H}, \mathrm{d}, J=8.8 \mathrm{~Hz}), 8.14(1 \mathrm{H}, \mathrm{d}, J=7.4 \mathrm{~Hz}) ;{ }^{13} \mathrm{C}$ NMR (150 MHz, CDCl $\left.{ }_{3}\right) \delta 14.1\left(\mathrm{CH}_{3}\right), 22.7\left(\mathrm{CH}_{2} \times 2\right), 28.1\left(\mathrm{CH}_{2}\right), 29.3\left(\mathrm{CH}_{2} \times 2\right), 29.4\left(\mathrm{CH}_{2}\right), 29.5\left(\mathrm{CH}_{2}\right)$, $29.6\left(\mathrm{CH}_{2}\right), 29.7\left(\mathrm{CH}_{2}\right), 31.9\left(\mathrm{CH}_{2}\right), 33.6(\mathrm{CH}), 104.5(\mathrm{C}), 113.2(\mathrm{C}), 115.0\left(\mathrm{CH}, J_{\mathrm{C}-\mathrm{F}}=20.8 \mathrm{~Hz}\right), 115.9(\mathrm{CH}$, $\left.J_{\mathrm{C}-\mathrm{F}}=22.1 \mathrm{~Hz}\right), 116.8(\mathrm{CH}), 117.4(\mathrm{C}), 120.0(\mathrm{C}), 123.2(\mathrm{CH}), 124.5\left(\mathrm{CH}, J_{\mathrm{C}-\mathrm{F}}=3.1 \mathrm{~Hz}\right), 124.8(\mathrm{CH}), 130.2$ $\left(\mathrm{CH}, J_{\mathrm{C}-\mathrm{F}}=9.0 \mathrm{~Hz}\right), 133.1(\mathrm{CH}), 143.0(\mathrm{C}), 147.7(\mathrm{C}), 151.2(\mathrm{C}), 152.6(\mathrm{C}), 154.5(\mathrm{C}), 160.2(\mathrm{C}), 162.9(\mathrm{C}$, $\left.J_{\mathrm{C}-\mathrm{F}}=246.1 \mathrm{~Hz}\right), 179.3(\mathrm{C}), 181.4(\mathrm{C})$; EIMS m/z (\%) $544\left(\mathrm{M}^{+}, 100\right), 450$ (16), 404 (12), 309 (12), 307 (9), 279 (5); HREIMS 544.2240 (calcd for $\mathrm{C}_{33} \mathrm{H}_{33} \mathrm{O}_{6} \mathrm{~F}\left(\mathrm{M}^{+}\right)$544.2261); IR $\left(\mathrm{CHCl}_{3}\right) v_{\max } 2924,2852,2288,2167$, $1699,1638,1613,1561,1492,1454,1376,1329,1233,1188 \mathrm{~cm}^{-1}$.

\subsection{9-Hydroxy-7-(4-nitrophenyl)-10-undecylchromeno[4,3-b]chromene-6,8,11(7H)-trione (4e)}

Following the general procedure described above, $24.8 \mathrm{mg}(64 \%)$ of $4 \mathbf{e}$ were obtained as an amorphous violet solid. ${ }^{1} \mathrm{H}$ NMR $\left(400 \mathrm{MHz}, \mathrm{C}_{6} \mathrm{D}_{6}\right) \delta: 1.11(3 \mathrm{H}, \mathrm{t}, J=6.1 \mathrm{~Hz}), 1.48(16 \mathrm{H}, \mathrm{bs}), 1.84$ $(2 \mathrm{H}, \mathrm{t}, J=7.0 \mathrm{~Hz}), 2.79(2 \mathrm{H}, \mathrm{t}, J=6.3 \mathrm{~Hz}), 5.06(1 \mathrm{H}, \mathrm{s}), 6.83(1 \mathrm{H}, \mathrm{s}), 7.00(1 \mathrm{H}, \mathrm{t}, J=7.6 \mathrm{~Hz}), 7.06(1 \mathrm{H}$, $\mathrm{d}, J=8.1 \mathrm{~Hz}), 7.12(1 \mathrm{H}, \mathrm{t}, J=7.3 \mathrm{~Hz}), 7.27(2 \mathrm{H}, \mathrm{d}, J=8.3 \mathrm{~Hz}), 7.89(2 \mathrm{H}, \mathrm{d}, J=8.2 \mathrm{~Hz}), 8.18(1 \mathrm{H}, \mathrm{d}$, $J=7.8 \mathrm{~Hz}) ;{ }^{13} \mathrm{C} \mathrm{NMR}\left(100 \mathrm{MHz}, \mathrm{CDCl}_{3}\right) \delta 14.1\left(\mathrm{CH}_{3}\right), 22.7\left(\mathrm{CH}_{2} \times 2\right), 28.0\left(\mathrm{CH}_{2}\right), 29.3\left(\mathrm{CH}_{2} \times 2\right), 29.5$ $\left(\mathrm{CH}_{2} \times 2\right), 29.6\left(\mathrm{CH}_{2} \times 2\right), 31.9\left(\mathrm{CH}_{2}\right), 34.1(\mathrm{CH}), 103.9(\mathrm{C}), 112.9(\mathrm{C}), 116.8(\mathrm{C}), 116.9(\mathrm{CH}), 120.5(\mathrm{C}), 123.3$ (CH), 123.9 (CHx2), $125.0(\mathrm{CH}), 129.9(\mathrm{CHx} 2), 133.5(\mathrm{CH}), 147.5(\mathrm{C}), 147.6(\mathrm{C}), 147.9(\mathrm{C}), 151.3(\mathrm{C}), 152.8$ (C), 154.7 (C), 160.2 (C), 179.1 (C), 181.4 (C); EIMS m/z (\%) $571\left(\mathrm{M}^{+}, 100\right), 450$ (20), 449 (44), 431 (20), 309 (14), 306 (11); HREIMS 571.2201 (calcd for $\mathrm{C}_{33} \mathrm{H}_{33} \mathrm{O}_{8} \mathrm{~N}\left(\mathrm{M}^{+}\right)$571.2206); IR $\left(\mathrm{CHCl}_{3}\right) v_{\max } 2923$, 2852, $1718,1639,1612,1557,1517,1458,1345,1294,1229,1184,1102 \mathrm{~cm}^{-1}$. 


\subsection{7-(3-Fluoro-4-methoxyphenyl)-9-hydroxy-10-undecylchromeno[4,3-b]chromene-6,8,11(7H)-trione (4f)}

Following the general procedure described above, $25.3 \mathrm{mg}(65 \%)$ of $4 \mathrm{f}$ were obtained as an amorphous violet solid. ${ }^{1} \mathrm{H}$ NMR $\left(400 \mathrm{MHz}, \mathrm{C}_{6} \mathrm{D}_{6}\right) \delta 1.11(3 \mathrm{H}, \mathrm{t}, J=6.1 \mathrm{~Hz}), 1.48(16 \mathrm{H}, \mathrm{s}), 1.81(2 \mathrm{H}$, t, $J=6.6 \mathrm{~Hz}), 2.75(2 \mathrm{H}, \mathrm{m}), 3.36(3 \mathrm{H}, \mathrm{s}), 5.15(1 \mathrm{H}, \mathrm{s}), 6.57(1 \mathrm{H}, \mathrm{t}, J=8.6 \mathrm{~Hz}), 6.85(1 \mathrm{H}, \mathrm{s}), 6.98(1 \mathrm{H}, \mathrm{t}$, $J=7.6 \mathrm{~Hz}), 7.05(1 \mathrm{H}, \mathrm{d}, J=8.4 \mathrm{~Hz}), 7.08(1 \mathrm{H}, \mathrm{dd}, J=7.4,1.1 \mathrm{~Hz}), 7.29(1 \mathrm{H}, \mathrm{d}, J=7.5 \mathrm{~Hz}), 7.45(1 \mathrm{H}, \mathrm{d}, J=$ $10.9 \mathrm{~Hz}), 8.16(1 \mathrm{H}, \mathrm{d}, J=7.9 \mathrm{~Hz}) ;{ }^{13} \mathrm{C}$ NMR $(150 \mathrm{MHz}, \mathrm{DMSO}-\mathrm{d} 6) \delta: 14.4\left(\mathrm{CH}_{3}\right), 22.5\left(\mathrm{CH}_{2}\right), 22.7\left(\mathrm{CH}_{2}\right)$, $28.4\left(\mathrm{CH}_{2}\right), 29.1\left(\mathrm{CH}_{2}\right), 29.4\left(\mathrm{CH}_{2} \times 2\right), 29.5\left(\mathrm{CH}_{2} \times 2\right), 29.6\left(\mathrm{CH}_{2}\right), 31.7\left(\mathrm{CH}_{2}\right), 33.3(\mathrm{CH}), 56.3\left(\mathrm{CH}_{3}\right), 104.9$ (C), $113.7(\mathrm{C}), 113.9(\mathrm{C}), 116.6(\mathrm{C}), 116.9(\mathrm{CH}), 117.1(\mathrm{CH}), 118.1\left(\mathrm{CH}, J_{\mathrm{C}-\mathrm{F}}=4.2 \mathrm{~Hz}\right), 123.1(\mathrm{CH}), 125.4$ (CH), $125.5(\mathrm{CH}), 133.5(\mathrm{CH}), 135.2(\mathrm{C}), 146.7(\mathrm{C}), 147.8(\mathrm{C}), 151.0(\mathrm{C}), 151.5\left(\mathrm{C}, J_{\mathrm{C}-\mathrm{F}}=242.6 \mathrm{~Hz}\right), 152.4$ (C), 154.2 (C), 160.3 (C), $177.7(\mathrm{C}), 183.3$ (C); EIMS m/z (\%) $574\left(\mathrm{M}^{+}, 100\right), 450$ (17), 449 (20), 448 (23), 435 (23), 434 (48), 323 (14), 309 (36); HREIMS 574.2330 (calcd for $\mathrm{C}_{34} \mathrm{H}_{35} \mathrm{O}_{7} \mathrm{~F}\left(\mathrm{M}^{+}\right)$574.2367); IR $\left(\mathrm{CHCl}_{3}\right)$ $v_{\max } 3344,2924,2853,2482,1721,1639,1612,1558,1517,1456,1394,1337,1283,1232,1184,1123 \mathrm{~cm}^{-1}$.

\subsection{7-(3,4-Dimethoxyphenyl)-9-hydroxy-10-undecylchromeno[4,3-b]chromene-6,8,11(7H)-trione (4g)}

Following the general procedure described above, $27.1 \mathrm{mg}(68 \%)$ of $4 \mathrm{~g}$ were obtained as an amorphous violet solid. ${ }^{1} \mathrm{H}$ NMR $\left(400 \mathrm{MHz}, \mathrm{C}_{6} \mathrm{D}_{6}\right) \delta 0.91(3 \mathrm{H}, \mathrm{t}, J=6.6 \mathrm{~Hz}), 1.28(16 \mathrm{H}, \mathrm{bs}), 1.64(2 \mathrm{H}$, m), $2.60(2 \mathrm{H}, \mathrm{m}), 3.32(3 \mathrm{H}, \mathrm{s}), 3.45(3 \mathrm{H}, \mathrm{s}), 5.04(1 \mathrm{H}, \mathrm{s}), 6.44(1 \mathrm{H}, \mathrm{m}), 6.74(1 \mathrm{H}, \mathrm{m}), 6.79(1 \mathrm{H}, \mathrm{m}), 6.87$ $(1 \mathrm{H}, \mathrm{t}, J=7.1 \mathrm{~Hz}), 6.91(1 \mathrm{H}, \mathrm{d}, J=8.5 \mathrm{~Hz}), 7.29(1 \mathrm{H}, \mathrm{s}), 8.02(1 \mathrm{H}, \mathrm{d}, J=6.8 \mathrm{~Hz}) ;{ }^{13} \mathrm{C} \mathrm{NMR}(100 \mathrm{MHz}$, $\left.\mathrm{CDCl}_{3}\right) \delta 14.1\left(\mathrm{CH}_{3}, \mathrm{C}-24\right), 22.6\left(\mathrm{CH}_{2}, \mathrm{C}-14\right), 22.7\left(\mathrm{CH}_{2}, \mathrm{C}-23\right), 28.2\left(\mathrm{CH}_{2}, \mathrm{C}-15\right), 29.3\left(\mathrm{CH}_{2}, \mathrm{C}-16\right), 29.4$ $\left(\mathrm{CH}_{2}, \mathrm{C}-17\right), 29.6\left(\mathrm{CH}_{2}, \mathrm{C}-18\right), 29.7\left(\mathrm{CH}_{2} \times 4\right), 31.9\left(\mathrm{CH}_{2}\right), 33.3(\mathrm{CH}), 55.8\left(\mathrm{CH}_{3}\right), 56.1\left(\mathrm{CH}_{3}\right), 105.1(\mathrm{C})$, $111.1(\mathrm{CH}), 112.6(\mathrm{C}), 113.3(\mathrm{C}), 116.8(\mathrm{CH}), 120.7(\mathrm{CH}), 123.1(\mathrm{CH}), 124.7(\mathrm{CH}), 128.9(\mathrm{C}), 131.3(\mathrm{C})$, $132.8(\mathrm{CH}), 133.5(\mathrm{CH}), 147.4(\mathrm{C}), 148.6(\mathrm{C}), 148.8(\mathrm{C}), 151.4(\mathrm{C}), 152.5(\mathrm{C}), 154.0(\mathrm{C}), 160.5(\mathrm{C}), 179.5(\mathrm{C})$, 181.9 (C); EIMS m/z (\%): $586\left(\mathrm{M}^{+}, 100\right), 492$ (12), 450 (33), 429 (17), 428 (88), 342 (14), 310 (62), 288 (14); HREIMS: 586.2584 (calcd for $\mathrm{C}_{35} \mathrm{H}_{38} \mathrm{O}_{8}\left(\mathrm{M}^{+}\right)$586.2567); IR $\left(\mathrm{CHCl}_{3}\right) v_{\max } 2922,2952,1713,1631,1559$, $1514,1455,1330,1268,1230,1143,1048,1025 \mathrm{~cm}^{-1}$.

\subsection{7-(Benzo[d][1,3]dioxo-5-yl)-9-hydroxy-10-undecylchromeno[4,3-b]chromene-6,8,11(7H)-trione (4h)}

Following the general procedure described above, $22.9 \mathrm{mg}(59 \%)$ of $4 \mathrm{~h}$ were obtained as an amorphous violet solid. ${ }^{1} \mathrm{H}$ NMR $\left(400 \mathrm{MHz}, \mathrm{C}_{6} \mathrm{D}_{6}\right) \delta 1.11(3 \mathrm{H}, \mathrm{t}, J=5.4 \mathrm{~Hz}), 1.50(16 \mathrm{H}, \mathrm{bs}), 1.81(2 \mathrm{H}$, m), $2.75(2 \mathrm{H}, \mathrm{d}, J=8.7 \mathrm{~Hz}), 5.13(1 \mathrm{H}, \mathrm{s}), 5.37(2 \mathrm{H}, \mathrm{d}, J=8.8 \mathrm{~Hz}), 5.38(1 \mathrm{H}, \mathrm{s}), 6.70(1 \mathrm{H}, \mathrm{d}, J=7.1 \mathrm{~Hz}), 6.94$ $(1 \mathrm{H}, \mathrm{d}, J=9.3 \mathrm{~Hz}), 6.99(1 \mathrm{H}, \mathrm{d}, J=7.4 \mathrm{~Hz}), 7.03(1 \mathrm{H}, \mathrm{d}, J=8.0 \mathrm{~Hz}), 7.08(1 \mathrm{H}, \mathrm{d}, J=8.0 \mathrm{~Hz}), 7.56(1 \mathrm{H}$, s), $8.17(1 \mathrm{H}, \mathrm{d}, J=9.2 \mathrm{~Hz}) ;{ }^{13} \mathrm{C} \mathrm{NMR}(150 \mathrm{MHz}, \mathrm{DMSO}-\mathrm{d} 6) \delta 14.4\left(\mathrm{CH}_{3}\right), 22.6\left(\mathrm{CH}_{2}\right), 22.7\left(\mathrm{CH}_{2}\right), 28.3$ $\left(\mathrm{CH}_{2}\right), 29.1\left(\mathrm{CH}_{2}\right), 29.4\left(\mathrm{CH}_{2} \times 2\right), 29.5\left(\mathrm{CH}_{2} \times 2\right), 29.6\left(\mathrm{CH}_{2}\right), 31.7\left(\mathrm{CH}_{2}\right), 33.7(\mathrm{CH}), 101.5\left(\mathrm{CH}_{2}\right), 105.2(\mathrm{C})$, $108.4(\mathrm{CH}), 109.9(\mathrm{CH}), 113.7(\mathrm{C}), 117.0(\mathrm{C}), 117.1(\mathrm{CH}), 118.1(\mathrm{C}), 122.6(\mathrm{CH}), 123.0(\mathrm{CH}), 125.4(\mathrm{CH})$, 129.2 (C), $131.8(\mathrm{C}), 133.5(\mathrm{CH}), 136.2(\mathrm{C}), 146.8(\mathrm{C}), 147.6(\mathrm{C}), 152.3(\mathrm{C}), 154.1(\mathrm{C}), 160.4(\mathrm{C}), 177.9$ (C), 183.0 (C, C-8); EIMS m/z (\%) $570\left(\mathrm{M}^{+}, 100\right), 450$ (22), 449 (13), 430 (16), 429 (50), 320 (14), 309 (36), 306 (12); HREIMS 570.2260 (calcd for $\mathrm{C}_{34} \mathrm{H}_{34} \mathrm{O}_{8}\left(\mathrm{M}^{+}\right)$570.2254); IR $\left(\mathrm{CHCl}_{3}\right) v_{\max } 2921,2852,1706,1635$, $1559,1490,1442,1329,1293,1229,1187,1102,1040 \mathrm{~cm}^{-1}$.

\subsection{9-Hydroxy-7-phenyl-10-undecylchromeno[4,3-b]chromene-6,8,11(7H)-trione (4i)}

Following the general procedure described above, $22.1 \mathrm{mg}(62 \%)$ of $4 \mathbf{i}$ were obtained as an amorphous violet solid. ${ }^{1} \mathrm{H}$ NMR $\left(400 \mathrm{MHz}, \mathrm{C}_{6} \mathrm{D}_{6}\right) \delta 0.91(3 \mathrm{H}, \mathrm{t}, J=5.6 \mathrm{~Hz}), 1.28(16 \mathrm{H}, \mathrm{bs}), 1.60$ $(2 \mathrm{H}, \mathrm{t}, J=7.5 \mathrm{~Hz}), 2.54(2 \mathrm{H}, \mathrm{d}, J=6.6 \mathrm{~Hz}), 5.03(1 \mathrm{H}, \mathrm{s}), 6.57(1 \mathrm{H}, \mathrm{s}), 6.80(2 \mathrm{H}, \mathrm{t}, J=7.1 \mathrm{~Hz}), 6.88(1 \mathrm{H}$, $\mathrm{d}, J=7.9 \mathrm{~Hz}), 6.95(1 \mathrm{H}, \mathrm{t}, J=7.2 \mathrm{~Hz}), 7.04(2 \mathrm{H}, \mathrm{t}, J=7.9 \mathrm{~Hz}), 7.42(2 \mathrm{H}, \mathrm{d}, J=7.0 \mathrm{~Hz}), 7.98(1 \mathrm{H}, \mathrm{d}$, $J=6.7 \mathrm{~Hz}) ;{ }^{13} \mathrm{C} \mathrm{NMR}\left(100 \mathrm{MHz}, \mathrm{CDCl}_{3}\right) \delta: 14.1\left(\mathrm{CH}_{3}\right), 22.7\left(\mathrm{CH}_{2} \times 2\right), 28.1\left(\mathrm{CH}_{2}, \mathrm{C}-22\right), 29.3\left(\mathrm{CH}_{2} \times 2\right)$, $29.4\left(\mathrm{CH}_{2}\right), 29.5\left(\mathrm{CH}_{2}\right), 29.6\left(\mathrm{CH}_{2}\right), 29.7\left(\mathrm{CH}_{2}\right), 31.9\left(\mathrm{CH}_{2}\right), 33.8(\mathrm{CH}), 105.2(\mathrm{C}), 113.3(\mathrm{C}), 116.8(\mathrm{CH})$, $117.9(\mathrm{C}), 119.8(\mathrm{C}), 123.2(\mathrm{CH}), 124.7(\mathrm{CH}), 127.9(\mathrm{CH}), 128.7(\mathrm{CHx} 4), 132.9(\mathrm{CH}), 140.7(\mathrm{C}), 147.7(\mathrm{C})$, $151.2(\mathrm{C}), 152.6$ (C), 154.3 (C), 160.2 (C), 179.5 (C), 181.5 (C); EIMS m/z (\%) $526\left(\mathrm{M}^{+}, 100\right), 449$ (19), 448 
(10), 387 (17), 386 (34), 310 (18), 280 (8); HREIMS: 526.2353 (calcd for $\mathrm{C}_{33} \mathrm{H}_{34} \mathrm{O}_{6}\left(\mathrm{M}^{+}\right)$526.2355); IR $\left(\mathrm{CHCl}_{3}\right) v_{\max } 2924,2853,1701,1637,1614,1556,1455,1375,1329,1296,1231,1186,1099,1048 \mathrm{~cm}^{-1}$.

\subsection{7-Hexyl-9-hydroxy-10-undecylchromeno[4,3-b]chromene-6,8,11(7H)-trione (4j)}

Following the general procedure described above, $24.7 \mathrm{mg}(68 \%)$ of $4 \mathbf{j}$ were obtained as an amorphous violet solid. ${ }^{1} \mathrm{H}$ NMR $\left(400 \mathrm{MHz}, \mathrm{CD}_{3} \mathrm{OD}\right) \delta: 0.79(3 \mathrm{H}, \mathrm{t}, J=5.6 \mathrm{~Hz}), 0.88(3 \mathrm{H}, \mathrm{t}, J=6.2 \mathrm{~Hz})$, $1.24(26 \mathrm{H}, \mathrm{bs}), 1.80(2 \mathrm{H}, \mathrm{m}), 2.40(2 \mathrm{H}, \mathrm{m}), 4.0(1 \mathrm{H}, \mathrm{s}), 7.38(1 \mathrm{H}, \mathrm{d}, J=7.9 \mathrm{~Hz}), 7.45(1 \mathrm{H}, \mathrm{t}, J=7.6 \mathrm{~Hz}), 7.68$ $(1 \mathrm{H}, \mathrm{t}, J=7.9 \mathrm{~Hz}), 8.19(1 \mathrm{H}, \mathrm{d}, J=7.1 \mathrm{~Hz}) ;{ }^{13} \mathrm{C} \mathrm{NMR}\left(100 \mathrm{MHz}, \mathrm{CDCl}_{3}\right) \delta 14.0\left(\mathrm{CH}_{3}\right), 14.1\left(\mathrm{CH}_{3}\right), 22.6$ $\left.\left(\mathrm{CH}_{2}\right), 22.7\left(\mathrm{CH}_{2}\right), 25.1\left(\mathrm{CH}_{2}\right), 28.1\left(\mathrm{CH}_{2}\right), 29.2\left(\mathrm{CH}_{2}\right), 29.3\left(\mathrm{CH}_{2}\right), 29.4\left(\mathrm{CH}_{2}\right), 29.5\left(\mathrm{CH}_{2}\right), 29.6\left(\mathrm{CH}_{2} \mathrm{x}\right)\right)$, $29.7\left(\mathrm{CH}_{2}\right), 31.7\left(\mathrm{CH}_{2}\right), 31.9\left(\mathrm{CH}_{2}\right), 32.7(\mathrm{CH}), 104.6(\mathrm{C}), 113.5(\mathrm{C}), 116.8(\mathrm{CH}), 117.9(\mathrm{C}), 119.7(\mathrm{C}), 123.1$ $(\mathrm{CH}), 124.6(\mathrm{CH}), 132.8(\mathrm{CH}), 149.4(\mathrm{C}), 151.3(\mathrm{C}), 152.5(\mathrm{C}), 155.8(\mathrm{C}), 160.9(\mathrm{C}), 179.3(\mathrm{C}), 182.0(\mathrm{C})$; EIMS $m / z(\%) 534\left(\mathrm{M}^{+}, 0.10\right), 451(26), 449\left(\mathrm{M}^{+}-\mathrm{C}_{6} \mathrm{H}_{13}, 100\right), 323$ (4), 310 (16), 308 (8); HREIMS 534.2932 (calcd for $\mathrm{C}_{33} \mathrm{H}_{42} \mathrm{O}_{6}\left(\mathrm{M}^{+}\right)$534.2981); IR $\left(\mathrm{CHCl}_{3}\right) v_{\max } 3350,2925,2855,1720,1641,1611,1555,1458,1390$, $1346,1288,1235,1185 \mathrm{~cm}^{-1}$.

\subsection{9-Hydroxy-7-propyl-10-undecylchromeno[4,3-b]chromene-6,8,11(7H)-trione (4k)}

Following the general procedure described above, $12.0 \mathrm{mg}(37 \%)$ of $4 \mathbf{k}$ were obtained as an amorphous violet solid. ${ }^{1} \mathrm{H}$ NMR $\left(400 \mathrm{MHz}, \mathrm{CDCl}_{3}\right) \delta: 0.87(6 \mathrm{H}), 1.25(18 \mathrm{H}, \mathrm{bs}), 1.44(2 \mathrm{H}, \mathrm{m}), 1.77(2 \mathrm{H}$, $\mathrm{t}, J=16.6 \mathrm{~Hz}), 2.41(2 \mathrm{H}, \mathrm{m}), 4.01(1 \mathrm{H}, \mathrm{s}), 7.40(1 \mathrm{H}, \mathrm{d}, J=8.4 \mathrm{~Hz}), 7.45(1 \mathrm{H}, \mathrm{t}, J=8.0 \mathrm{~Hz}), 7.69(1 \mathrm{H}, \mathrm{t}, J=$ $8.1 \mathrm{~Hz}), 8.19(1 \mathrm{H}, \mathrm{d}, J=7.0 \mathrm{~Hz})$; EIMS $m / z(\%) 492\left(\mathrm{M}^{+}, 1\right), 450(56), 449\left(\mathrm{M}^{+}-\mathrm{C}_{3} \mathrm{H}_{7}, 100\right), 421(4), 310$ (11); HREIMS 492.2517 (calcd for $\mathrm{C}_{30} \mathrm{H}_{36} \mathrm{O}_{6}\left(\mathrm{M}^{+}\right)$492.2512); IR $\left(\mathrm{CHCl}_{3}\right) v_{\max } 2930,2859,2491,1725$, $1642,1612,1560,1461,1394,1340,1290,1243,1189,1092 \mathrm{~cm}^{-1}$.

\subsection{7-Ethyl-9-hydroxy-10-undecylchromeno[4,3-b]chromene-6,8,11(7H)-trione (41)}

Following the general procedure described above, $12.7 \mathrm{mg}(39 \%)$ of 41 were obtained as an amorphous violet solid. ${ }^{1} \mathrm{H}$ NMR $\left(400 \mathrm{MHz}, \mathrm{CDCl}_{3}\right) \delta 0.78(3 \mathrm{H}, \mathrm{t}, J=6.9 \mathrm{~Hz}), 0.87(3 \mathrm{H}, \mathrm{t}, J=5.8 \mathrm{~Hz})$, $1.25(16 \mathrm{H}, \mathrm{bs}), 1.51(2 \mathrm{H}, \mathrm{t}, J=7.4 \mathrm{~Hz}), 1.82(1 \mathrm{H}, \mathrm{m}), 2.00(1 \mathrm{H}, \mathrm{m}), 2.50(2 \mathrm{H}, \mathrm{t}, J=8.3 \mathrm{~Hz}), 4.19(1 \mathrm{H}, \mathrm{t}$, $J=5.6 \mathrm{~Hz}), 7.14(1 \mathrm{H}, \mathrm{s}), 7.38(2 \mathrm{H}, \mathrm{t}, J=7.3,7.7 \mathrm{~Hz}), 7.61(1 \mathrm{H}, \mathrm{t}, J=7.4 \mathrm{~Hz}), 8.01(1 \mathrm{H}, \mathrm{d}, J=7.7 \mathrm{~Hz})$; ${ }^{13} \mathrm{C} \mathrm{NMR}\left(100 \mathrm{MHz}, \mathrm{CDCl}_{3}\right) \delta 9.1\left(\mathrm{CH}_{3}\right), 14.1\left(\mathrm{CH}_{3}\right), 22.6\left(\mathrm{CH}_{2}\right), 22.7\left(\mathrm{CH}_{2}\right), 25.1\left(\mathrm{CH}_{2}\right), 28.1\left(\mathrm{CH}_{2}\right)$, $28.9\left(\mathrm{CH}_{2}\right), 29.3\left(\mathrm{CH}_{2}\right), 29.4\left(\mathrm{CH}_{2}\right), 29.5\left(\mathrm{CH}_{2}\right), 29.6\left(\mathrm{CH}_{2} \times 2\right), 29.6\left(\mathrm{CH}_{2}\right), 31.9(\mathrm{CH}), 103.9(\mathrm{C}), 113.3(\mathrm{C})$, $116.7(\mathrm{CH}), 117.5(\mathrm{C}), 119.7(\mathrm{C}), 122.9(\mathrm{CH}), 124.7(\mathrm{CH}), 132.7(\mathrm{CH}), 149.6(\mathrm{C}), 151.2(\mathrm{C}), 152.5(\mathrm{C}), 156.0$ (C), 160.9 (C), 179.4 (C), 182.0 (C); EIMS m/z (\%) $492\left(\mathrm{M}^{+}, 0.04\right), 450$ (33), $449\left(\mathrm{M}^{+}-\mathrm{C}_{2} \mathrm{H}_{5}, 100\right), 421$ (5), 310 (11), 309 (8); HREIMS: 478.2361 (calcd for $\mathrm{C}_{29} \mathrm{H}_{34} \mathrm{O}_{6}\left(\mathrm{M}^{+}\right)$478.2355); IR $\left(\mathrm{CHCl}_{3}\right) v_{\max } 3352,2924$, $2853,1721,1640,1611,1458,1390,1347,1288,1233,1185,1114,1036 \mathrm{~cm}^{-1}$.

3.28. General Procedures for the Multicomponent Reaction between Embelin (1), Aldehyde (2), And 2-Naphthol (5), with Indium Trichloride as Catalyst

Embelin (1) (20.0 mg, $0.068 \mathrm{mmol})$, the corresponding aldehyde (2) $(0.068 \mathrm{mmol})$, and 2-naphthol (5) $(1.0 \mathrm{mmol})$ were grinded in a mortar for $5 \mathrm{~min}$. Then, $3.1 \mathrm{mg}$ of $\mathrm{InCl}_{3}(20 \mathrm{~mol} \%)$ was added and the reaction mixture was grinded again for $15 \mathrm{~min}$, placed in a sealed tube and kept in an oven at $120^{\circ} \mathrm{C}$ for $1.5 \mathrm{~h}$. The resulting crude was purified by preparative-TLC chromatography using toluene: EtOAc (9:1) as eluant.

\subsection{2-(4-Bromophenyl)-10-hydroxy-9-undecyl-8H-benzo[a]xanthene-8,11(12H)-dione (5a)}

Following the general procedure described above, $26.0 \mathrm{mg}(65 \%)$ of $5 \mathbf{a}$ were obtained as an amorphous violet solid. ${ }^{1} \mathrm{H}$ NMR $\left(400 \mathrm{MHz}, \mathrm{C}_{6} \mathrm{D}_{6}\right) \delta 1.11(3 \mathrm{H}, \mathrm{t}, J=6.2 \mathrm{~Hz}), 1.47(16 \mathrm{H}, \mathrm{bs}), 1.80(2 \mathrm{H}$, $\mathrm{t}, J=6.5 \mathrm{~Hz}), 2.76(2 \mathrm{H}, \mathrm{q}, J=6.7 \mathrm{~Hz}), 5.70(1 \mathrm{H}, \mathrm{s}), 7.05(1 \mathrm{H}, \mathrm{s}), 7.19(2 \mathrm{H}, \mathrm{d}, J=8.5 \mathrm{~Hz}), 7.23(2 \mathrm{H}, \mathrm{d}$, $J=8.5 \mathrm{~Hz}), 7.30(2 \mathrm{H}, \mathrm{t}, J=10.8,7.7 \mathrm{~Hz}), 7.50(1 \mathrm{H}, \mathrm{d}, J=9.0 \mathrm{~Hz}), 7.55(1 \mathrm{H}, \mathrm{d}, J=8.9 \mathrm{~Hz}), 7.66(1 \mathrm{H}, \mathrm{d}, J=$ $8.1 \mathrm{~Hz}), 7.92(1 \mathrm{H}, \mathrm{d}, J=8.4 \mathrm{~Hz}) ;{ }^{13} \mathrm{C}$ NMR $\left(100 \mathrm{MHz}, \mathrm{CDCl}_{3}\right) \delta 14.0\left(\mathrm{CH}_{3}, \mathrm{C}-23\right), 22.6\left(\mathrm{CH}_{2}\right), 22.7\left(\mathrm{CH}_{2}\right)$, $28.0\left(\mathrm{CH}_{2}\right), 29.3\left(\mathrm{CH}_{2}\right), 29.4\left(\mathrm{CH}_{2}\right), 29.5\left(\mathrm{CH}_{2}\right), 29.6\left(\mathrm{CH}_{2} \times 3\right), 31.9\left(\mathrm{CH}_{2}\right), 34.8(\mathrm{CH}), 115.1(\mathrm{C}), 115.7$ 
(C), $117.5(\mathrm{CH}), 119.2(\mathrm{C}), 121.2(\mathrm{C}), 123.3(\mathrm{CH}), 125.6(\mathrm{CH}), 127.5(\mathrm{CH}), 128.7(\mathrm{CH}), 130.0(\mathrm{CH}), 130.4$ (CHx2), 130.6 (C), 131.8 (CHx2), 132.0 (C), 141.8 (C), 147.5 (C), 149.3 (C), 151.1 (C), 180.5 (C), 182.1 (C); EIMS m/z (\%) $586\left(\mathrm{M}^{+}, 1\right), 447$ (18), 445 (15), 433 (22), 432 (33), $431\left(\mathrm{M}^{+}-\mathrm{C}_{6} \mathrm{H}_{4} \mathrm{Br}, 100\right), 403$ (4), 303 (10), 292 (13), 291 (12), 289 (11); HREIMS 588.1680 (calcd for $\mathrm{C}_{34} \mathrm{H}_{35} \mathrm{O}_{4}{ }^{81} \mathrm{Br}\left(\mathrm{M}^{+}\right.$) 588.1698), 586.1752 (calcd for $\mathrm{C}_{34} \mathrm{H}_{35} \mathrm{O}_{4}{ }^{79} \mathrm{Br}\left(\mathrm{M}^{+}\right)$586.1719); IR $\left(\mathrm{CHCl}_{3}\right) v_{\max } 2923,2852,1630,1593,1516,1463,1394,1327,1214$, $1177,1115,1072,1009,974,814 \mathrm{~cm}^{-1}$.

\subsection{2-(4-Chlorophenyl)-10-hydroxy-9-undecyl-8H-benzo[a]xanthene-8,11(12H)-dione (5b)}

Following the general procedure described above, $44.0 \mathrm{mg}(81 \%)$ of $\mathbf{5 b}$ were obtained as an amorphous violet solid. ${ }^{1} \mathrm{H}$ NMR $\left(400 \mathrm{MHz}, \mathrm{C}_{6} \mathrm{D}_{6}\right) \delta: 1.11(3 \mathrm{H}, \mathrm{t}), 1.47(16 \mathrm{H}, \mathrm{bs}), 1.79(2 \mathrm{H}, \mathrm{m}), 2.75$ $(2 \mathrm{H}, \mathrm{q}, J=6.6 \mathrm{~Hz}), 5.73(1 \mathrm{H}, \mathrm{s}), 6.99(1 \mathrm{H}, \mathrm{s}), 7.08(2 \mathrm{H}, \mathrm{d}, J=8.2 \mathrm{~Hz}), 7.27(2 \mathrm{H}, \mathrm{d}, J=8.2 \mathrm{~Hz}), 7.33$ $(2 \mathrm{H}, \mathrm{t}, J=7.5 \mathrm{~Hz}), 7.50(1 \mathrm{H}, \mathrm{d}, J=8.9 \mathrm{~Hz}), 7.55(1 \mathrm{H}, \mathrm{d}, J=8.4 \mathrm{~Hz}), 7.66(1 \mathrm{H}, \mathrm{d}, J=8.0 \mathrm{~Hz}), 7.91(1 \mathrm{H}$, $\mathrm{d}, J=8.2 \mathrm{~Hz}) ;{ }^{13} \mathrm{C}$ NMR $(100 \mathrm{MHz}, \mathrm{DMSO}-\mathrm{d} 6) \delta 14.0\left(\mathrm{CH}_{3}\right), 22.6\left(\mathrm{CH}_{2}\right), 22.7\left(\mathrm{CH}_{2}\right), 28.0\left(\mathrm{CH}_{2}\right), 29.3$ $\left(\mathrm{CH}_{2}\right), 29.4\left(\mathrm{CH}_{2}\right), 29.5\left(\mathrm{CH}_{2}\right), 29.6\left(\mathrm{CH}_{2} \times 3\right), 31.9\left(\mathrm{CH}_{2}\right), 34.8(\mathrm{CH}), 115.1(\mathrm{C}), 115.7(\mathrm{C}), 117.5(\mathrm{CH})$, $119.2(\mathrm{C}), 121.2(\mathrm{C}), 123.3(\mathrm{CH}), 125.6(\mathrm{CH}), 127.5(\mathrm{CH}), 128.7(\mathrm{CH}), 130.0(\mathrm{CH}), 130.4(\mathrm{CHx} 2), 130.6(\mathrm{C})$, 131.8 (CHx2), 132.0 (C), 141.8 (C), 147.5 (C), 149.3 (C), 151.1 (C), 180.5 (C), 182.1 (C); EIMS m/z (\%) 542 $\left(\mathrm{M}^{+}, 1\right), 433$ (19), 432 (49), $431\left(\mathrm{M}^{+}-\mathrm{C}_{6} \mathrm{H}_{4} \mathrm{Cl}, 100\right), 404$ (16), 403 (21), 402 (21), 401 (36), 303 (16), 292 (21), 288 (19); HREIMS 544.2135 (calcd for $\mathrm{C}_{34} \mathrm{H}_{35} \mathrm{O}_{4}{ }^{37} \mathrm{Cl}\left(\mathrm{M}^{+}\right)$544.2194), 542.2208 (calcd for $\mathrm{C}_{34} \mathrm{H}_{35} \mathrm{O}_{4}{ }^{35} \mathrm{Cl}$ $\left(\mathrm{M}^{+}\right)$542.2224); IR $\left(\mathrm{CHCl}_{3}\right) v_{\max } 2929,2858,1635,1598,1520,1493,1467,1399,1330,1216,1182,1093$, $977,825,745 \mathrm{~cm}^{-1}$.

\subsection{2-(4-Fluorophenyl)-10-hydroxy-9-undecyl-8H-benzo[a]xanthene-8,11(12H)-dione (5c)}

Following the general procedure described above, $21.5 \mathrm{mg}(60 \%)$ of $5 \mathrm{c}$ were obtained as an amorphous violet solid. ${ }^{1} \mathrm{H}$ NMR $\left(400 \mathrm{MHz}, \mathrm{C}_{6} \mathrm{D}_{6}\right) \delta: 1.11(3 \mathrm{H}, \mathrm{t}, J=6.0 \mathrm{~Hz}), 1.47(16 \mathrm{H}, \mathrm{bs}), 1.78(2 \mathrm{H}, \mathrm{t}$, $J=7.2 \mathrm{~Hz}), 2.74(2 \mathrm{H}, \mathrm{q}, J=7.4 \mathrm{~Hz}), 5.77(1 \mathrm{H}, \mathrm{s}), 6.77(2 \mathrm{H}, \mathrm{t}, J=8.6 \mathrm{~Hz}), 6.99(1 \mathrm{H}, \mathrm{s}), 7.32(4 \mathrm{H}, \mathrm{dd}, J=8.8$, $4.0 \mathrm{~Hz}), 7.51(1 \mathrm{H}, \mathrm{d}, J=8.8 \mathrm{~Hz}), 7.55(1 \mathrm{H}, \mathrm{d}, J=8.8 \mathrm{~Hz}), 7.66(1 \mathrm{H}, \mathrm{d}, J=7.8 \mathrm{~Hz}), 7.95(1 \mathrm{H}, \mathrm{d}, J=8.4 \mathrm{~Hz})$; ${ }^{13} \mathrm{C} \mathrm{NMR}\left(100 \mathrm{MHz}, \mathrm{CDCl}_{3}\right) \delta 14.1\left(\mathrm{CH}_{3}\right), 22.6\left(\mathrm{CH}_{2}\right), 22.7\left(\mathrm{CH}_{2}\right), 28.1\left(\mathrm{CH}_{2}\right), 29.3\left(\mathrm{CH}_{2}\right), 29.4\left(\mathrm{CH}_{2}\right)$, $29.5\left(\mathrm{CH}_{2}\right), 29.6\left(\mathrm{CH}_{2}\right), 29.7\left(\mathrm{CH}_{2} \times 2\right), 31.9\left(\mathrm{CH}_{2}\right), 34.6(\mathrm{CH}), 115.4(\mathrm{C}), 115.6\left(\mathrm{CHx} 2, J_{\mathrm{C}-\mathrm{F}}=21.4 \mathrm{~Hz}\right)$, $116.0(\mathrm{C}), 117.6(\mathrm{CH}), 119.1(\mathrm{C}), 123.4(\mathrm{CH}), 125.6(\mathrm{CH}), 127.4(\mathrm{CH}), 128.7(\mathrm{CH}), 129.9(\mathrm{CH}), 130.3(\mathrm{CHx} 2$, $\left.J_{\mathrm{C}-\mathrm{F}}=8.0 \mathrm{~Hz}\right), 130.7(\mathrm{C}), 132.0(\mathrm{C}), 138.6(\mathrm{C}), 147.5(\mathrm{C}), 149.2(\mathrm{C}), 151.2(\mathrm{C}), 161.7\left(\mathrm{C}, J_{\mathrm{C}-\mathrm{F}}=245.2 \mathrm{~Hz}\right)$, 180.7 (C), $182.2(\mathrm{C})$; EIMS m/z (\%) $526\left(\mathrm{M}^{+}, 1\right), 508$ (34), $433(13), 432(41), 431\left(\mathrm{M}^{+}-\mathrm{C}_{6} \mathrm{H}_{4} \mathrm{~F}, 100\right), 387(15)$, 386 (25), 302 (13), 292 (15), 289 (13), 280 (16), 268 (13), 230 (17), 218 (11); HREIMS 526.2542 (calcd for $\mathrm{C}_{34} \mathrm{H}_{35} \mathrm{O}_{4} \mathrm{~F}\left(\mathrm{M}^{+}\right)$526.2519); IR $\left(\mathrm{CHCl}_{3}\right) v_{\max } 2928,2857,2475,1621,1598,1509,1467,1393,1320,1228$, $1182,1073,1048,975,834,818,746 \mathrm{~cm}^{-1}$.

\subsection{2-(3-Fluorophenyl)-10-hydroxy-9-undecyl-8H-benzo[a]xanthene-8,11(12H)-dione (5d)}

Following the general procedure described above, $22.9 \mathrm{mg}(64 \%)$ of $\mathbf{5 d}$ were obtained as an amorphous violet solid. ${ }^{1} \mathrm{H}$ NMR $\left(400 \mathrm{MHz}, \mathrm{C}_{6} \mathrm{D}_{6}\right) \delta 1.11(3 \mathrm{H}, \mathrm{t}, J=7.2 \mathrm{~Hz}), 1.48(16 \mathrm{H}, \mathrm{bs}), 1.76(2 \mathrm{H}, \mathrm{t}$, $J=7.0 \mathrm{~Hz}), 2.72(2 \mathrm{H}, \mathrm{d}, J=8.0 \mathrm{~Hz}), 5.79(1 \mathrm{H}, \mathrm{s}), 6.69(1 \mathrm{H}, \mathrm{t}, J=8.4 \mathrm{~Hz}), 6.84(1 \mathrm{H}, \mathrm{q}, J=6.4 \mathrm{~Hz}), 6.97(1 \mathrm{H}$, s), $7.13(1 \mathrm{H}, \mathrm{d}, J=8.2 \mathrm{~Hz}), 7.28(2 \mathrm{H}, \mathrm{t}, J=8.1 \mathrm{~Hz}), 7.48(1 \mathrm{H}, \mathrm{d}, J=8.7 \mathrm{~Hz}), 7.53(2 \mathrm{H}, \mathrm{d}, J=8.8 \mathrm{~Hz}), 7.64$ $(1 \mathrm{H}, \mathrm{d}, J=8.0 \mathrm{~Hz}), 7.93(1 \mathrm{H}, \mathrm{d}, J=8.1 \mathrm{~Hz}) ;{ }^{13} \mathrm{C} \mathrm{NMR}\left(100 \mathrm{MHz}, \mathrm{CDCl}_{3}\right) \delta 14.0\left(\mathrm{CH}_{3}\right), 22.6\left(\mathrm{CH}_{2}\right), 22.7$ $\left(\mathrm{CH}_{2}\right), 28.1\left(\mathrm{CH}_{2}\right), 29.3\left(\mathrm{CH}_{2}\right), 29.4\left(\mathrm{CH}_{2}\right), 29.5\left(\mathrm{CH}_{2}\right), 29.6\left(\mathrm{CH}_{2}\right), 31.9\left(\mathrm{CH}_{2}\right), 35.0(\mathrm{CH}), 114.2(\mathrm{CH}$, $\left.J_{\mathrm{C}-\mathrm{F}}=20.6 \mathrm{~Hz}\right), 115.8\left(\mathrm{CH}, J_{\mathrm{C}-\mathrm{F}}=20.9 \mathrm{~Hz}\right), 117.6(\mathrm{CH}), 119.2(\mathrm{C}), 123.4(\mathrm{CH}), 124.3\left(\mathrm{CH}, J_{\mathrm{C}-\mathrm{F}}=2.6 \mathrm{~Hz}\right)$, $125.6(\mathrm{CH}), 127.5\left(\mathrm{CH}, J_{\mathrm{C}-\mathrm{F}}=9.4 \mathrm{~Hz}\right), 127.8(\mathrm{C}), 128.0(\mathrm{C}), 128.7(\mathrm{CH}), 130.0(\mathrm{CH}), 130.1(\mathrm{CH}), 130.7$ (C), $132.0(\mathrm{C}), 145.1\left(\mathrm{C}, J_{\mathrm{C}-\mathrm{F}}=5.78 \mathrm{~Hz}\right), 147.6(\mathrm{C}), 149.4(\mathrm{C}), 151.2(\mathrm{C}), 162.9\left(\mathrm{C}, J_{\mathrm{C}-\mathrm{F}}=245.8 \mathrm{~Hz}\right), 180.5$ (C), 182.0 (C); EIMS m/z (\%) $526\left(\mathrm{M}^{+}, 1\right), 434$ (12), 433 (26), 432 (78), $431\left(\mathrm{M}^{+}-\mathrm{C}_{6} \mathrm{H}_{4} \mathrm{~F}, 100\right), 388$ (10), 387 (25), 386 (24), 302 (13), 292 (16), 289 (10), 275 (6), 263 (8); HREIMS 526.2496 (calcd for $\mathrm{C}_{34} \mathrm{H}_{35} \mathrm{O}_{4} \mathrm{~F}\left(\mathrm{M}^{+}\right.$) 526.2519); IR $\left(\mathrm{CHCl}_{3}\right) v_{\max } 2925,2854,2480,1616,1591,1448,1323,1237,1211,1124,1073,975,864$, $820 \mathrm{~cm}^{-1}$. 


\subsection{0-Hydroxy-12-(4-nitrophenyl)-9-undecyl-8H-benzo[a]xanthene-8,11(12H)-dione (5e)}

Following the general procedure described above, $32.7 \mathrm{mg}(87 \%)$ of $\mathbf{5 e}$ were obtained as an amorphous violet solid. ${ }^{1} \mathrm{H}$ NMR $\left(400 \mathrm{MHz}, \mathrm{CDCl}_{3}\right) \delta 0.87(3 \mathrm{H}, \mathrm{t}, J=6.3 \mathrm{~Hz}), 1.24(16 \mathrm{H}, \mathrm{bs}), 1.47(2 \mathrm{H}$, $\mathrm{m}, J=6.9 \mathrm{~Hz}), 2.46(2 \mathrm{H}, \mathrm{t}, J=7.3 \mathrm{~Hz}), 5.93(1 \mathrm{H}, \mathrm{s}), 7.13(1 \mathrm{H}, \mathrm{s}), 7.46(2 \mathrm{H}, \mathrm{t}, J=7.4,3.6 \mathrm{~Hz}), 7.53(2 \mathrm{H}$, $\mathrm{d}, J=8.4 \mathrm{~Hz}), 7.58(1 \mathrm{H}, \mathrm{d}, J=9.0 \mathrm{~Hz}), 7.76(1 \mathrm{H}, \mathrm{d}, J=8.0 \mathrm{~Hz}), 7.85(1 \mathrm{H}, \mathrm{d}, J=6.7 \mathrm{~Hz}), 7.89(1 \mathrm{H}, \mathrm{d}$, $J=9.0 \mathrm{~Hz}), 8.08(2 \mathrm{H}, \mathrm{d}, J=8.4 \mathrm{~Hz}) ;{ }^{13} \mathrm{C} \mathrm{NMR}\left(100 \mathrm{MHz}, \mathrm{CDCl}_{3}\right) \delta 14.1\left(\mathrm{CH}_{3}\right), 22.6\left(\mathrm{CH}_{2}\right), 22.7\left(\mathrm{CH}_{2}\right)$, 28.1 $\left(\mathrm{CH}_{2}\right), 29.3\left(\mathrm{CH}_{2}\right), 29.4\left(\mathrm{CH}_{2}\right), 29.5\left(\mathrm{CH}_{2}\right), 29.6\left(\mathrm{CH}_{2} \times 3\right), 31.9\left(\mathrm{CH}_{2}\right), 35.4(\mathrm{CH}), 114.3(\mathrm{C}), 114.9(\mathrm{C})$, 117.6 (CH), $119.6(\mathrm{C}), 123.1(\mathrm{CH}), 123.9(\mathrm{CHx} 2), 125.8(\mathrm{CH}), 127.8(\mathrm{CH}), 128.9(\mathrm{CH}), 129.7(\mathrm{CHx} 2), 130.5$ (CH), 130.9 (C), 132.1 (C), 146.9 (C), 147.6 (C), 149.7 (C), 151.2 (C), 180.2 (C), 181.9 (C); EIMS m/z (\%) $553\left(\mathrm{M}^{+}, 100\right), 432$ (27), $431\left(\mathrm{M}^{+}-\mathrm{C}_{6} \mathrm{H}_{4} \mathrm{NO}_{2}, 81\right), 414$ (20), 413(29), 302 (13), 291(15), 290 (12). HREIMS: 553.2459 (calcd. for $\mathrm{C}_{34} \mathrm{H}_{35} \mathrm{O}_{6} \mathrm{~N}\left(\mathrm{M}^{+}\right)$553.2464). IR $\left(\mathrm{CHCl}_{3}\right) v_{\max }$ : 3339, 2925, 2854, 1631, 1594, 1516, $1463,1343,1213,1179,1113,1072,976 \mathrm{~cm}^{-1}$.

\subsection{2-(3-Fluoro-4-methoxyphenyl)-10-hydroxy-9-undecyl-8H-benzo[a]xanthene-8,11(12H)-dione (5f)}

Following the general procedure described above, $30.6 \mathrm{mg}(81 \%)$ of $\mathbf{5 f}$ were obtained as an amorphous violet solid. Twenty milligrams of embelin $(0.068 \mathrm{mmol}), 9.79 \mathrm{mg}(0.068 \mathrm{mmol})$ of 2-naphthol and $10.58 \mathrm{mg}$ of 3-fluoro-4-methoxybenzaldehyde $(0.068 \mathrm{mmol})$ were grinded for $5 \mathrm{~min}$, then $3.1 \mathrm{mg}(20 \mathrm{~mol} \%)$ of $\mathrm{InCl}_{3}$ was added and the reaction mixture was grinded again for $15 \mathrm{~min}$. After $1.5 \mathrm{~h}$ at $120^{\circ} \mathrm{C}$, the resulting crude was purified by preparative-TLC using toluene: EtOAc (9:1) as eluant, to provide ${ }^{1} \mathrm{H}$ NMR $\left(400 \mathrm{MHz}, \mathrm{C}_{6} \mathrm{D}_{6}\right) \delta: 1.11(3 \mathrm{H}, \mathrm{t}, J=6.2 \mathrm{~Hz}), 1.47(16 \mathrm{H}, \mathrm{bs}), 1.78(2 \mathrm{H}, \mathrm{t}, J=$ $6.8 \mathrm{~Hz}), 2.75(2 \mathrm{H}, \mathrm{d}, J=6.7 \mathrm{~Hz}), 3.26(3 \mathrm{H}, \mathrm{s}), 5.77(1 \mathrm{H}, \mathrm{s}), 6.39(1 \mathrm{H}, \mathrm{t}, J=8.5 \mathrm{~Hz}), 7.01(1 \mathrm{H}, \mathrm{d}, J=8.2 \mathrm{~Hz})$, $7.31(2 \mathrm{H}, \mathrm{m}, J=7.8 \mathrm{~Hz}), 7.51(1 \mathrm{H}, \mathrm{d}, J=8.8 \mathrm{~Hz}), 7.55(1 \mathrm{H}, \mathrm{d}, J=4.8 \mathrm{~Hz}), 7.58(1 \mathrm{H}, \mathrm{dd}, J=8.4,0.9 \mathrm{~Hz})$, $7.67(1 \mathrm{H}, \mathrm{d}, J=8.0 \mathrm{~Hz}), 7.99(1 \mathrm{H}, \mathrm{d}, J=8.3 \mathrm{~Hz}) ;{ }^{13} \mathrm{C} \mathrm{NMR}\left(100 \mathrm{MHz}, \mathrm{CDCl}_{3}\right) \delta 14.1\left(\mathrm{CH}_{3}\right), 22.6\left(\mathrm{CH}_{2}\right)$, $22.7\left(\mathrm{CH}_{2}\right), 28.1\left(\mathrm{CH}_{2}\right), 29.3\left(\mathrm{CH}_{2}\right), 29.4\left(\mathrm{CH}_{2}\right), 29.5\left(\mathrm{CH}_{2}\right), 29.6\left(\mathrm{CH}_{2} \times 3\right), 31.9\left(\mathrm{CH}_{2}\right), 34.3(\mathrm{CH}), 56.1$ $\left(\mathrm{CH}_{3}\right), 113.2(\mathrm{C}), 115.2(\mathrm{C}), 115.8(\mathrm{C}), 116.5\left(\mathrm{CH}, J_{\mathrm{C}-\mathrm{F}}=18 \mathrm{~Hz}\right), 117.6(\mathrm{CH}), 119.1(\mathrm{C}), 123.4(\mathrm{CH}), 124.3$ $\left(\mathrm{CH}, J_{\mathrm{C}-\mathrm{F}}=1.8 \mathrm{~Hz}\right), 125.5(\mathrm{CH}), 127.4\left(\mathrm{CH}, J_{\mathrm{C}-\mathrm{F}}=4 \mathrm{~Hz}\right), 128.7(\mathrm{CH}), 129.9(\mathrm{CH}), 130.7(\mathrm{CH}), 130.9(\mathrm{C})$, $132.0(\mathrm{C}), 135.8(\mathrm{C}), 146.6\left(\mathrm{C}, J_{\mathrm{C}-\mathrm{F}}=8.8 \mathrm{~Hz}\right), 147.5(\mathrm{C}), 149.2(\mathrm{C}), 151.2(\mathrm{C}), 152.2\left(\mathrm{C}, J_{\mathrm{C}-\mathrm{F}}=244.7 \mathrm{~Hz}\right)$, 180.7 (C), 182.2 (C); EIMS m/z (\%) $556\left(\mathrm{M}^{+}, 100\right), 433$ (13), $432(29), 431\left(\mathrm{M}^{+}-\mathrm{C}_{7} \mathrm{H}_{6} \mathrm{O}_{1} \mathrm{~F}, 65\right), 415(28)$, 413(29), 304 (19), 302 (16), 291(26), 290 (14), 289 (13), 288 (22), 263 (11); HREIMS 556.2629 (calcd. for $\mathrm{C}_{35} \mathrm{H}_{37} \mathrm{O}_{5} \mathrm{~F}\left(\mathrm{M}^{+}\right)$556.2625). IR $\left(\mathrm{CHCl}_{3}\right) v_{\max } 2930,2858,1635,1598,1518,1466,1443,1331,1275,1214$, $1122,1075,978 \mathrm{~cm}^{-1}$.

\subsection{2-(3,4-Dimethoxyphenyl)-10-hydroxy-9-undecyl-8H-benzo[a]xanthene-8,11(12H)-dione (5g)}

Following the general procedure described above, $32.1 \mathrm{mg}(83 \%)$ of $5 \mathrm{~g}$ were obtained as an amorphous violet solid. ${ }^{1} \mathrm{H}$ NMR $\left(400 \mathrm{MHz}, \mathrm{CDCl}_{3}\right) \delta: 0.87(3 \mathrm{H}, \mathrm{t}), 1.25(16 \mathrm{H}, \mathrm{bs}), 1.47(2 \mathrm{H}, \mathrm{t}$, $J=9.2 \mathrm{~Hz}), 2.45(2 \mathrm{H}, \mathrm{t}, J=7.0 \mathrm{~Hz}), 3.76(3 \mathrm{H}, \mathrm{s}), 3.79(3 \mathrm{H}, \mathrm{s}), 5.75(1 \mathrm{H}, \mathrm{s}), 6.69(1 \mathrm{H}, \mathrm{d}, J=8.2 \mathrm{~Hz}), 6.80$ $(1 \mathrm{H}, \mathrm{d}, J=7.9 \mathrm{~Hz}), 6.92(1 \mathrm{H}, \mathrm{s}), 7.19(1 \mathrm{H}, \mathrm{s}), 7.44(2 \mathrm{H}, \mathrm{m}), 7.54(1 \mathrm{H}, \mathrm{d}, J=8.9 \mathrm{~Hz}), 7.83(2 \mathrm{H}, \mathrm{t}, J=8.4 \mathrm{~Hz})$, $7.89(1 \mathrm{H}, \mathrm{d}, J=7.8 \mathrm{~Hz}) ;{ }^{13} \mathrm{C}$ NMR $\left(100 \mathrm{MHz}, \mathrm{CDCl}_{3}\right) \delta 14.1\left(\mathrm{CH}_{3}\right), 22.6\left(\mathrm{CH}_{2}\right), 22.7\left(\mathrm{CH}_{2}\right), 28.1\left(\mathrm{CH}_{2}\right)$, $29.3\left(\mathrm{CH}_{2}\right), 29.4\left(\mathrm{CH}_{2}\right), 29.5\left(\mathrm{CH}_{2}\right), 29.6\left(\mathrm{CH}_{2}\right), 29.7\left(\mathrm{CH}_{2} \times 2\right), 31.9\left(\mathrm{CH}_{2}\right), 34.8(\mathrm{CH}), 55.8\left(\mathrm{CH}_{3}\right), 55.9$ $\left(\mathrm{CH}_{3}\right), 111.2(\mathrm{CH}), 112.0(\mathrm{CH}), 115.8(\mathrm{C}), 116.3(\mathrm{C}), 117.5(\mathrm{CH}), 119.0(\mathrm{C}), 121.1(\mathrm{CH}), 123.6(\mathrm{CH}), 125.5$ $(\mathrm{CH}), 127.3(\mathrm{CH}), 128.6(\mathrm{CH}), 128.8(\mathrm{C}), 129.7(\mathrm{CH}), 130.9(\mathrm{C}), 131.9(\mathrm{C}), 135.5(\mathrm{C}), 147.6(\mathrm{C}), 148.0(\mathrm{C})$, 149.1 (C), 151.2 (C), 180.8 (C), 182.4 (C); EIMS m/z (\%) $568\left(\mathrm{M}^{+}, 100\right), 432(17), 431\left(\mathrm{M}^{+}-\mathrm{C}_{8} \mathrm{H}_{9} \mathrm{O}_{2}, 27\right), 428$ (18), 317 (14), 292 (14), 288 (10); HREIMS: 568.2806 (calcd. for $\mathrm{C}_{36} \mathrm{H}_{40} \mathrm{O}_{6}\left(\mathrm{M}^{+}\right)$568.2825). IR $\left(\mathrm{CHCl}_{3}\right)$ $v_{\max } 2926,2854,1635,1594,1513,1461,1328,1266,1231,1140,1072,1026,812 \mathrm{~cm}^{-1}$.

\subsection{2-(Benzo[d]dioxo-5-yl)-10-hydroxy-9-undecyl-8H-benzo[a]xanthene-8,11(12H)-dione (5h)}

Following the general procedure described above, $33.0 \mathrm{mg}(88 \%)$ of $5 \mathrm{~h}$ were obtained as an amorphous violet solid. ${ }^{1} \mathrm{H}$ NMR $\left(400 \mathrm{MHz}, \mathrm{C}_{6} \mathrm{D}_{6}\right) \delta 1.11(3 \mathrm{H}, \mathrm{t}, J=5.9 \mathrm{~Hz}), 1.47(16 \mathrm{H}, \mathrm{bs}), 1.77(2 \mathrm{H}$, m), $2.74(2 \mathrm{H}, \mathrm{d}, J=4.9 \mathrm{~Hz}), 5.29(2 \mathrm{H}, \mathrm{dd}, J=5.9,4.2 \mathrm{~Hz}), 5.79(1 \mathrm{H}, \mathrm{s}), 6.59(1 \mathrm{H}, \mathrm{d}, J=7.7 \mathrm{~Hz}), 6.93(1 \mathrm{H}$, 
$\mathrm{d}, J=8.2 \mathrm{~Hz}), 7.06(1 \mathrm{H}, \mathrm{d}, J=8.9 \mathrm{~Hz}), 7.24(1 \mathrm{H}, \mathrm{s}), 7.31(1 \mathrm{H}, \mathrm{d}, J=7.8 \mathrm{~Hz}), 7.50(2 \mathrm{H}, \mathrm{m}), 7.66(1 \mathrm{H}, \mathrm{d}, J=$ $7.8 \mathrm{~Hz}), 8.08(1 \mathrm{H}, \mathrm{d}, J=8.5 \mathrm{~Hz}) ;{ }^{13} \mathrm{C}$ NMR $\left(100 \mathrm{MHz}, \mathrm{CDCl}_{3}\right) \delta 14.1\left(\mathrm{CH}_{3}\right), 22.6\left(\mathrm{CH}_{2}, \mathrm{C}-22\right), 22.7\left(\mathrm{CH}_{2}\right.$, C-13), $28.1\left(\mathrm{CH}_{2}, \mathrm{C}-14\right), 29.3\left(\mathrm{CH}_{2}, \mathrm{C}-15\right), 29.4\left(\mathrm{CH}_{2}, \mathrm{C}-16\right), 29.5\left(\mathrm{CH}_{2}, \mathrm{C}-17\right), 29.6\left(\mathrm{CH}_{2} \times 2\right), 29.7\left(\mathrm{CH}_{2}\right)$, $31.9\left(\mathrm{CH}_{2}\right), 34.9(\mathrm{CH}), 101.1\left(\mathrm{CH}_{2}\right), 108.2(\mathrm{CH}), 109.1(\mathrm{CH}), 115.7(\mathrm{C}), 116.3(\mathrm{C}), 117.6(\mathrm{CH}), 119.1(\mathrm{C})$, $122.1(\mathrm{CH}), 123.5(\mathrm{CH}), 125.5(\mathrm{CH}), 127.3(\mathrm{CH}), 128.7(\mathrm{CH}), 129.7(\mathrm{CH}), 130.8(\mathrm{C}), 131.9(\mathrm{C}), 136.8(\mathrm{C})$, 146.5 (C), 147.4 (C), 147.9 (C), 149.3 (C), 153.2 (C), 180.8 (C), 182.4 (C); EIMS m/z (\%) 552 (M $\left.\mathrm{M}^{+}, 100\right), 430$ $\left(\mathrm{M}^{+}-\mathrm{C}_{7} \mathrm{H}_{5} \mathrm{O}_{2}, 10\right), 413(11), 412$ (34), 330 (4), 300(30), 292 (18), 291 (18), 230(14); HREIMS 552.2494 (calcd for $\mathrm{C}_{35} \mathrm{H}_{36} \mathrm{O}_{6}\left(\mathrm{M}^{+}\right)$552.2512); IR $\left(\mathrm{CHCl}_{3}\right) v_{\max } 2924,2853,1626,1554,1486,1441,1395,1329,1213,1174$, $1116,1037,973,926,810,744 \mathrm{~cm}^{-1}$.

\subsection{0-Hydroxy-12-phenyl-9-undecyl-8H-benzo[a]xanthene-8,11(12H)-dione (5i)}

Following the general procedure described above, $28.3 \mathrm{mg}(82 \%)$ of $5 \mathbf{i}$ were obtained as an amorphous violet solid. ${ }^{1} \mathrm{H}$ NMR $\left(400 \mathrm{MHz}, \mathrm{C}_{6} \mathrm{D}_{6}\right) \delta 1.11(3 \mathrm{H}, \mathrm{t}, J=5.5 \mathrm{~Hz}), 1.48(16 \mathrm{H}, \mathrm{bs}), 1.76(2 \mathrm{H}, \mathrm{t}$, $J=7.2 \mathrm{~Hz}), 2.71(2 \mathrm{H}, \mathrm{d}, J=8.7 \mathrm{~Hz}), 5.87(1 \mathrm{H}, \mathrm{s}), 7.02(1 \mathrm{H}, \mathrm{t}, J=6.8 \mathrm{~Hz}), 7.14(2 \mathrm{H}, \mathrm{t}, J=7.2 \mathrm{~Hz}), 7.27$ $(1 \mathrm{H}, \mathrm{t}, J=7.7 \mathrm{~Hz}), 7.32(1 \mathrm{H}, \mathrm{d}, J=7.7 \mathrm{~Hz}), 7.56(3 \mathrm{H}, \mathrm{t}, J=7.6 \mathrm{~Hz}), 7.65(1 \mathrm{H}, \mathrm{d}, J=7.6 \mathrm{~Hz}), 8.06(1 \mathrm{H}, \mathrm{d}$, $J=8.3 \mathrm{~Hz}$ ); EIMS m/z (\%): $508\left(\mathrm{M}^{+}, 0.99\right), 434$ (3), 433 (12), $432(35), 431\left(\mathrm{M}^{+}-\mathrm{C}_{6} \mathrm{H}_{5}, 100\right), 369$ (9), 368 (17), 302 (11), 292 (12). HREIMS: 508.2594 (calcd. para $\mathrm{C}_{34} \mathrm{H}_{36} \mathrm{O}_{4}\left(\mathrm{M}^{+}\right)$508.2614). IR $\left(\mathrm{CHCl}_{3}\right) v_{\max }$ : 2922, $2851,1631,1511,1385,1356,1330,1218,1176,1116,1078,975,751 \mathrm{~cm}^{-1}$.

\subsection{2-Hexyl-10-hydroxy-9-undecyl-8H-benzo[a]xanthene-8,11(12H)-dione (5j)}

Following the general procedure described above, $15.8 \mathrm{mg}(45 \%)$ of $5 \mathbf{j}$ were obtained as an amorphous violet solid. ${ }^{1} \mathrm{H}$ NMR $\left(500 \mathrm{MHz}, \mathrm{C}_{6} \mathrm{D}_{6}\right) \delta 0.87(3 \mathrm{H}, \mathrm{t}, J=7.2 \mathrm{~Hz}), 1.06(2 \mathrm{H}, \mathrm{m}), 1.11(3 \mathrm{H}, \mathrm{t}$, $J=6.6 \mathrm{~Hz}), 1.24(2 \mathrm{H}, \mathrm{m}), 1.38(2 \mathrm{H}, \mathrm{m}), 1.48(16 \mathrm{H}, \mathrm{bs}), 1.60(2 \mathrm{H}, \mathrm{m}), 1.87(2 \mathrm{H}, \mathrm{t}, J=6.9 \mathrm{~Hz}), 2.01(2 \mathrm{H}$, $\mathrm{m}), 2.85(2 \mathrm{H}, \mathrm{t}, J=8.5 \mathrm{~Hz}), 4.90(1 \mathrm{H}, \mathrm{t}, J=4.9 \mathrm{~Hz}), 7.41(2 \mathrm{H}, \mathrm{m}), 7.50(2 \mathrm{H}, \mathrm{d}, J=8.8 \mathrm{~Hz}), 7.71(1 \mathrm{H}, \mathrm{d}$, $J=8.0 \mathrm{~Hz}), 7.95(1 \mathrm{H}, \mathrm{d}, J=8.1 \mathrm{~Hz}) ;{ }^{13} \mathrm{C} \mathrm{NMR}\left(100 \mathrm{MHz}, \mathrm{CDCl}_{3}\right) \delta 13.9\left(\mathrm{CH}_{3}\right), 14.1\left(\mathrm{CH}_{3}\right), 22.5\left(\mathrm{CH}_{2}\right)$, $22.7\left(\mathrm{CH}_{2} \times 2\right), 24.9\left(\mathrm{CH}_{2} \mathrm{t}, \mathrm{C}-14\right), 28.2\left(\mathrm{CH}_{2}\right), 28.6\left(\mathrm{CH}_{2}\right), 29.2\left(\mathrm{CH}_{2}\right), 29.3\left(\mathrm{CH}_{2}\right), 29.4\left(\mathrm{CH}_{2}\right), 29.6\left(\mathrm{CH}_{2}\right)$, $29.7\left(\mathrm{CH}_{2} \times 3\right), 31.6\left(\mathrm{CH}_{2}\right), 34.9(\mathrm{CH}), 115.7(\mathrm{C}), 116.4(\mathrm{C}), 117.4(\mathrm{CH}), 118.9(\mathrm{C}), 122.9(\mathrm{CH}), 125.3(\mathrm{CH})$, 127.1 (CH), 128.8 (CHx2), 130.6 (C), 131.9 (C), $148.2(\mathrm{C}), 151.2(\mathrm{C}), 151.7$ (C), 180.6 (C), 182.5 (C); EIMS $\mathrm{m} / \mathrm{z}(\%) 516\left(\mathrm{M}^{+}, 0.05\right), 433$ (16), 432 (41), $431\left(\mathrm{M}^{+}-\mathrm{C}_{6} \mathrm{H}_{13}, 100\right), 334$ (27), 317 (19), 292 (12), 291 (13), 277 (27), 263 (20). HREIMS 516.3255 (calcd for $\mathrm{C}_{34} \mathrm{H}_{44} \mathrm{O}_{4}\left(\mathrm{M}^{+}\right)$516.3240); IR $\left(\mathrm{CHCl}_{3}\right) v_{\max } 3347,2927,2857$, $1633,1596,1521,1466,1332,1276,1209,1119,973,819,742 \mathrm{~cm}^{-1}$.

\subsection{0-Hydroxy-12-propyl-9-undecyl-8H-benzo[a]xanthene-8,11(12H)-dione (5k)}

Following the general procedure described above, $15.8 \mathrm{mg}(49 \%)$ of $\mathbf{5 k}$ were obtained as an amorphous violet solid. ${ }^{1} \mathrm{H}$ NMR $\left(400 \mathrm{MHz}, \mathrm{CDCl}_{3}\right) \delta: 0.74(3 \mathrm{H}, \mathrm{t}, J=7.1 \mathrm{~Hz}), 0.87(3 \mathrm{H}, \mathrm{t}, J=6.2 \mathrm{~Hz})$, $0.95(2 \mathrm{H}, \mathrm{m}), 1.26(16 \mathrm{H}, \mathrm{bs}), 1.52(2 \mathrm{H}, \mathrm{t}, J=7.7 \mathrm{~Hz}), 1.82(2 \mathrm{H}, \mathrm{m}), 2.50(2 \mathrm{H}, \mathrm{t}, J=7.2 \mathrm{~Hz}), 4.83(1 \mathrm{H}, \mathrm{t}, J=$ $4.8 \mathrm{~Hz}), 7.41(1 \mathrm{H}, \mathrm{d}, J=8.9 \mathrm{~Hz}), 7.49(1 \mathrm{H}, \mathrm{t}, J=7.5 \mathrm{~Hz}), 7.59(1 \mathrm{H}, \mathrm{t}, J=7.2 \mathrm{~Hz}), 7.76(1 \mathrm{H}, \mathrm{d}, J=8.9 \mathrm{~Hz})$, $7.85(1 \mathrm{H}, \mathrm{d}, J=8.0 \mathrm{~Hz}), 8.05(1 \mathrm{H}, \mathrm{d}, J=8.4 \mathrm{~Hz}) ;{ }^{13} \mathrm{C} \mathrm{NMR}\left(100 \mathrm{MHz}, \mathrm{CDCl}_{3}\right) \delta 13.9\left(\mathrm{CH}_{3}\right), 14.1\left(\mathrm{CH}_{3}\right)$, $18.3\left(\mathrm{CH}_{2}\right), 22.6\left(\mathrm{CH}_{2}\right), 22.7\left(\mathrm{CH}_{2}\right), 28.1\left(\mathrm{CH}_{2}\right), 28.6\left(\mathrm{CH}_{2}\right), 29.3\left(\mathrm{CH}_{2}\right), 29.4\left(\mathrm{CH}_{2}\right), 29.5\left(\mathrm{CH}_{2}\right), 29.6$ $\left(\mathrm{CH}_{2} \times 3\right), 31.9\left(\mathrm{CH}_{2}\right), 37.2(\mathrm{CH}), 115.8(\mathrm{C}), 116.5(\mathrm{C}), 117.4(\mathrm{CH}), 118.9(\mathrm{C}), 122.9(\mathrm{CH}), 125.4(\mathrm{CH}), 127.1$ (CH), 128.8 (CHx2), 130.7 (C), 131.9 (C), 148.2 (C), 151.2 (C), 151.8 (C), 180.6 (C), 182.5 (C); EIMS m/z (\%) $474\left(\mathrm{M}^{+}, 1\right), 433(8), 432(31), 431\left(\mathrm{M}^{+}-\mathrm{C}_{3} \mathrm{H}_{7}, 100\right), 389$ (7), 302 (7), 292 (8); HREIMS 474.2762 (calcd. for $\left.\mathrm{C}_{31} \mathrm{H}_{38} \mathrm{O}_{4}\left(\mathrm{M}^{+}\right) 474.2770\right)$; IR $\left(\mathrm{CHCl}_{3}\right) v_{\max } 2928,2857,1635,1597,1522,1465,1363,1335,1276,1213$, $1179,1118,1084 \mathrm{~cm}^{-1}$.

\subsection{2-Ethyl-10-hydroxy-9-undecyl-8H-benzo[a]xanthene-8,11(12H)-dione (51)}

Following the general procedure described above, $10.7 \mathrm{mg}(27 \%)$ of 51 were obtained as an amorphous violet solid. ${ }^{1} \mathrm{H}$ NMR $\left(400 \mathrm{MHz}, \mathrm{CDCl}_{3}\right) \delta 0.65(3 \mathrm{H}, \mathrm{t}, J=7.1 \mathrm{~Hz}), 0.87(3 \mathrm{H}, \mathrm{t}, J=5.9 \mathrm{~Hz})$, $1.25(16 \mathrm{H}, \mathrm{bs}), 1.51(2 \mathrm{H}, \mathrm{t}, J=8.0 \mathrm{~Hz}), 1.92(2 \mathrm{H}, \mathrm{m}), 2.50(2 \mathrm{H}, \mathrm{t}, J=6.9 \mathrm{~Hz}), 4.85(1 \mathrm{H}, \mathrm{t}, J=4.0 \mathrm{~Hz}), 7.41$ $(1 \mathrm{H}, \mathrm{d}, J=8.8 \mathrm{~Hz}), 7.48(1 \mathrm{H}, \mathrm{t}, J=7.4 \mathrm{~Hz}), 7.58(1 \mathrm{H}, \mathrm{d}, J=6.4 \mathrm{~Hz}), 7.77(1 \mathrm{H}, \mathrm{d}, J=8.8 \mathrm{~Hz}), 7.85(1 \mathrm{H}, \mathrm{d}$, 
$J=7.9 \mathrm{~Hz}), 8.04(1 \mathrm{H}, \mathrm{d}, J=7.9 \mathrm{~Hz}) ;{ }^{13} \mathrm{C} \mathrm{NMR}\left(100 \mathrm{MHz}, \mathrm{CDCl}_{3}\right) \delta 9.0\left(\mathrm{CH}_{3}\right), 14.1\left(\mathrm{CH}_{3}\right), 22.6\left(\mathrm{CH}_{2}\right)$, $22.7\left(\mathrm{CH}_{2}\right), 28.1\left(\mathrm{CH}_{2}\right), 29.3\left(\mathrm{CH}_{2}\right), 29.4\left(\mathrm{CH}_{2} \times 2\right), 29.5\left(\mathrm{CH}_{2} \times 2\right), 29.6\left(\mathrm{CH}_{2} \times 3\right), 31.9(\mathrm{CH}), 115.1(\mathrm{C}), 115.8$ (C), $117.4(\mathrm{CH}), 118.9(\mathrm{C}), 122.9(\mathrm{CH}), 125.4(\mathrm{CH}), 127.1(\mathrm{CH}), 128.8(\mathrm{CH}), 128.9(\mathrm{CH}), 130.7(\mathrm{C}), 131.9$ (C), 148.4 (C), 151.2 (C), 151.9 (C), 180.6 (C), 182.5 (C); EIMS m/z (\%) $460\left(\mathrm{M}^{+}, 1\right), 433$ (13), 432 (36), 431 $\left(\mathrm{M}^{+}-\mathrm{C}_{2} \mathrm{H}_{5}, 100\right), 302$ (5). HREIMS: 460.2610 (calcd for $\left.\mathrm{C}_{30} \mathrm{H}_{36} \mathrm{O}_{4}\left(\mathrm{M}^{+}\right) 460.2614\right)$ ); $\mathrm{IR}\left(\mathrm{CHCl}_{3}\right) v_{\max } 3379$, 2926, 2856, 1618, 1595, 1465, 1324, 1272, 1228, 1119, 1087, 969, $821 \mathrm{~cm}^{-1}$.

\subsection{Biological Assays}

Antibacterial activity was determined using the standard broth microdilution method as recommended by the National Committee for Clinical Laboratory Standards $[8,11,25]$. We used three Gram-positive bacterial strains; methicillin-sensitive Staphylococcus aureus ATCC25923 (MSSA), methicillin-resistant vancomycin-intermediate resistant Staphylococcus aureus NRS402 (VISA), and Enterococcus faecalis ATCC29212; as well as the Gram-negative Escherichia coli ATCC35218. Bacterial strains stored at $-80^{\circ} \mathrm{C}$ were first plated on brain heart infusion (BHI) agar and incubated at $37^{\circ} \mathrm{C}$ overnight followed by a second overnight growth in cation-adjusted Mueller-Hinton (MH) broth. Bacterial suspensions were then normalized in fresh $\mathrm{MH}$ broth and added to premade 1:2 serial dilutions of each tested compounds and control antibiotics in the same media. The range of concentrations was from 0.5 to 128 ( $\mu \mathrm{M}$ for the tested compounds and $\mu \mathrm{g} / \mathrm{mL}$ for the reference antibiotics) and the final volume was $200 \mu \mathrm{L}$. The expected initial concentration in all wells was $1 \times 10^{5}$ cells $/ \mathrm{mL}$. The minimum inhibitory concentration (MIC) was estimated by eye after $24 \mathrm{~h}$ of incubation at $37^{\circ} \mathrm{C}$ without shaking.

A similar procedure was used for the yeast Saccharomyces cerevisiae BY4741 wild-type strain [26]. In this case, the growing media was YPD and the inoculum was $\sim 2 \times 10^{4}$ cells $/ \mathrm{mL}$. The growth was measured at $30^{\circ} \mathrm{C}$ after $24 \mathrm{~h}$ and $48 \mathrm{~h}$.

\subsection{Calculation of Electrostatic Polar Potentials, Electron Density, and Fukui Indices}

The calculations of Density Functional Theory (DFT) was employed for optimization and minimization of geometry of the compounds shown in Scheme 2, as well as to examine the reactivity of the calculated compounds, their structural and electronic properties were obtained by parameters of reactivity and theoretical properties such as the energy values of highest occupied molecular orbital (HOMO) and lowest unoccupied molecular orbital (LUMO), electronic density and electrostatic potential using the B3LYP functional and the $6-31+G(d, p)$ basis set implemented in Jaguar-v.10.6 computational program [27,28]. Atomic Fukui indices were derived from Mulliken population of the highest occupied molecular orbital (HOMO) and the LUMO, were used to quantify electrophilicity of a molecule at a particular atomic site. The default convergence criterion implemented in Jaguar was used for self-consistent field (SCF) calculations (accuracy level = quick, convergence criteria: maximum iteration $=48$, and energy change $=5 \times 10^{-5}$ hartree) and optimization (maximum steps $=100$, convergence criteria $=$ default, initial Hessian $=$ Schlegel guess $[29,30]$.

\section{Conclusions}

In summary, three series of new embelin conjugates were obtained through an $\mathrm{InCl}_{3}$ catalyzed three component reaction from embelin (1), aldehydes and privileged substructures of antimicrobial interest such as 4-hydroxy-2H-pyran-2-one, 4-hydroxy-coumarin, and 2-naphthol. This MCR implies Knoevenagel condensation, Michael addition, intramolecular cyclization, and dehydration. Most part of the conjugates synthesized from 4-hydroxy-2H-pyran-2-one and 4-hydroxy-coumarin resulted to be active and selective toward Gram positive bacteria. Some structure-activity relationships were outlined and the most active compounds were $3 \mathbf{a}-3 \mathbf{c}, \mathbf{4 c}, \mathbf{4 d}$, and $4 \mathbf{g}$ with MICs around 1-2 $\mu \mathrm{M}$. The present results encourage further research with these compounds in order to develop novel antibiotic agents against Gram-positive bacteria. 
Supplementary Materials: The following are available online ${ }^{1} \mathrm{H}$ NMR and ${ }^{13} \mathrm{C}$ NMR spectra of compounds $3 a-31,4 a-41$ and $5 a-51$.

Author Contributions: G.F. and A.T. isolated and purified embelin. F.M. and I.L.-C. contributed to the performance of the biological experimental work. R.P. and P.M.-A. prepared, purified and characterized the embelin derivatives. Á.A., carried out the computational studies. A.E.-B., Á.A., and F.M., contributed in the conception, design, discussion of the results, drafting and financial support of the manuscript submitted. All authors read and approved the final version of the manuscript.

Funding: We gratefully acknowledge the financial support from the Spanish MICIU RTI2018-094356-B-C21 to AEB and BFU2017-83954-R to FM, Agencia Canaria de Investigación, Innovación y Sociedad de la Información Pro ID 2017010071 to AEB and ProID2017010167 to FM. These projects are also co-funded by the European Regional Development Fund (FEDER). PIO-CONICET SECITI N ${ }^{\circ} 0022$ and CICITCA-UNSJ to GF and AT.

Acknowledgments: PMA thanks to ACIISI for a pre-doctoral grant (FPI-Program). AA thanks the Cabildo de Tenerife (Agustín de Betancourt Program).

Conflicts of Interest: The authors declare no conflict of interest.

\section{References}

1. Kim, J.; Kim, H.; Park, S.B. Privileged structures: Efficient chemical "navigators" toward unexplored biologically relevant chemical spaces. J. Am. Chem. Soc. 2014, 136, 14629-14638. [CrossRef] [PubMed]

2. Heng, Z.; Ge, S.; Gao, M.; Jian, R.; Chen, X.; Xu, X.; Li, D.; Zhang, K.; Chen, W.-H. Synthesis and biological activity of embelin and its derivatives: An overview. Mini-Rev. Med. Chem. 2020, 20, 396-407.

3. Li, J.Y.; Chen, R.J.; Huang, L.T.; Lee, T.Y.; Lu, W.J.; Lin, K.H. Embelin as a novel inhibitor of PKC in the prevention of platelet activation and thrombus formation. J. Clin. Med. 2019, 8, 1724. [CrossRef] [PubMed]

4. Nigam, N.; Grover, A.; Goyal, S.; Katiyar, S.P.; Bhargava, P.; Wang, P.C.; Sundar, D.; Kaul, S.C.; Wadhwa, R. Targeting mortalin by embelin causes activation of tumor suppressor p53 and deactivation of metastatic signaling in human breast cancer cells. PLoS ONE 2015, 10, e0138192/1-e0138192/15. [CrossRef]

5. Filosa, R.; Peduto, A.; Schaible, A.M.; Krauth, V.; Weinigel, C.; Barz, D.; Petronzi, C.; Bruno, F.; Roviezzo, F.; Spaziano, G.; et al. Novel series of benzoquinones with high potency against 5-lipoxygenase in human polymorphonuclear leukocytes. Eur. J. Med. Chem. 2015, 94, 132-139. [CrossRef]

6. Avisetti, D.R.; Babu, K.S.; Kalivendi, S.V. Activation of p38/JNK pathway is responsible for embelin induced apoptosis in lung cancer cells: Transitional role of reactive oxygen species. PLoS ONE 2014, 9, e87050/1-e87050/10. [CrossRef]

7. Naik, S.R.; Niture, N.T.; Ansari, A.A.; Shah, P.D. Anti-diabetic activity of embelin: Involvement of cellular inflammatory mediators, oxidative stress and other biomarkers. Phytomedicine 2013, 20, 797-804. [CrossRef]

8. Peña, R.; Jimenez-Alonso, S.; Feresin, G.; Tapia, A.; Méndez-Alvarez, S.; Machin, F.; Ravelo, A.G.; Estevez-Braun, A. Multicomponent synthesis of antibacterial dihydropyridin and dihydropyran embelin derivatives. J. Org. Chem. 2013, 78, 7977-7985.

9. Martín-Acosta, P.; Haider, S.; Amesty, A.; Aichele, D.; Jose, J.; Estevez-Braun, A. A new family of densely functionalized fused-benzoquinones as potent human protein kinase CK2 inhibitors. Eur. J. Med. Chem. 2018, 144, 410-423. [CrossRef]

10. Jiménez-Alonso, S.; Pérez-Lomas, A.L.; Estévez-Braun, A.; Muñoz-Martinez, F.; Chávez-Orellana, H.; Ravelo, A.G.; Gamarro, F.; Castanys, S.; López, M. Bis-pyranobenzoquinones as a new family of reversal agents of the multidrug resistance phenotype mediated by P-glycoprotein in mammalian cells and the protozoan parasite Leishmania. J. Med. Chem. 2008, 51, 7132-7143.

11. Peña, R.; Martín-Acosta, P.; Feresin, G.E.; Tapia, A.; Machin, F.; Estevez-Braun, A. Domino synthesis of embelin derivatives with antibacterial activity. J. Nat. Prod. 2016, 79, 970-977.

12. Martín-Acosta, P.; Feresin, G.; Tapia, A.; Estévez-Braun, A. Microwave-assisted organocatalytic intramolecular Knoevenagel/Hetero Diels-Alder reaction with O-(arylpropynyloxy)-salicylaldehydes: Synthesis of polycyclic embelin derivatives. J. Org. Chem. 2016, 81, 9738-9756. [CrossRef] [PubMed]

13. Evans, B.E.; Rittle, K.E.; Bock, M.G.; Dipardo, R.M.; Freidinger, R.M.; Whitter, W.L.; Lundell, G.F.; Veber, D.F.; Anderson, P.S.; Chang, R.S.L.; et al. Methods for drug discovery. Development of potent, selective, orally effective cholecystokinin antagonists. J. Med. Chem. 1988, 31, 2235-2246. [CrossRef] [PubMed] 
14. Campanini-Salinas, J.; Campanini-Salinas, J.; Andrades-Lagos, J.; Vasquez-Velasquez, D.; Mella-Raipan, J. Novel classes of antibacterial drugs in clinical development, a hope in a post-antibiotic era. Curr. Top. Med. Chem. 2018, 18, 1188-1202. [CrossRef] [PubMed]

15. Josef, J. Design and discovery of new antibacterial agents: Advances, perspectives, challenges. Curr. Med. Chem. 2018, 25, 4972-5006.

16. Parr, R.G.; Yang, W. Density functional approach to the frontier-electron theory of chemical reactivity. J. Am. Chem. Soc. 1984, 106, 4049-4050. [CrossRef]

17. Yang, W.; Mortier, W.J. The use of global and local molecular parameters for the analysis of the gas-phase basicity of amines. J. Am. Chem. Soc. 1986, 108, 5708-5711. [CrossRef]

18. Kim, M.; Hwang, Y.S.; Cho, W.; Park, S.B. Synthesis of 3,5-disubstituted isoxazoles containing privileged substructures with a diverse display of polar surface area. ACS Comb. Sci. 2017, 19, 407-413. [CrossRef]

19. Jiménez-Alonso, S.; Guasch, J.; Estévez-Braun, A.; Ratera, I.; Veciana, J.; Ravelo, A.G. Electronic and cytotoxic properties of 2-amino-naphtho[2,3-b]furan-4,9-diones. J. Org. Chem. 2011, 76, 1634-1643.

20. Khurana, J.M.; Magoo, D. pTSA-catalyzed one-pot synthesis of 12-aryl-8,9,10,12-tetrahydrobenzo[ $a]$ xanthen-11-ones in ionic liquid and neat conditions. Tetrahedron Let. 2009, 50, 4777-4780. [CrossRef]

21. Liu, L.; Sarkisian, R.; Deng, Y.; Wang, H. Sc(OTf) ${ }_{3}$-Catalyzed Three-component cyclization of arylamines, $\beta, \gamma$-Unsaturated $\alpha$-Ketoesters, and 1,3-dicarbonyl compounds for the synthesis of highly substituted 1,4-dihydropyridines and tetrahydropyridines. J. Org. Chem. 2013, 78, 5751-5755. [CrossRef] [PubMed]

22. Stefani, H.A.; Manarin, F.; Souza, A.C.S.; Souza, F.B.; Frederico, B.; Ferraz, W.R. Three-component reaction for the synthesis of diverse $\beta$-unsaturated $\alpha$-amino esters. Tetrahedron 2014, 70, 3243-3248. [CrossRef]

23. Hueso-Falcón, I.; Amesty, A.; Martín, P.; López-Rodríguez, M.; Fernández-Pérez, L.; Estévez-Braun, A. Indium catalyzed solvent-free multicomponent synthesis of cytotoxic dibenzo[ $a, h]$ anthracenes from aldehydes, 2-hydroxy-1,4-naphthoquinone, and 2-naphthol. Tetrahedron 2014, 70, 8480-8487.

24. Feresin, G.E.; Tapia, A.; Sortino, M.; Zacchino, S.; de Arias, A.R.; Inchausti, A.; Yaluff, J.; Rodriguez, G.; Theoduloz, C.; Schmeda-Hirschmann, G. Bioactive alkyl phenols and embelin from Oxalis erythrorhiza. J. Ethnopharmacol. 2003, 88, 241-247. [CrossRef]

25. Oramas-Royo, S.; Pantoja, K.D.; Amesty, A.; Romero, C.; Lorenzo-Castrillejo, I.; Machín, F.; Estevez-Braun, A. Synthesis and antibacterial activity of new symmetric polyoxygenated dibenzofurans. Eur. J. Med. Chem. 2017, 141, 178-187. [CrossRef]

26. Ramos-Pérez, C.; Lorenzo-Castrillejo, I.; Quevedo, O.; García-Luis, J.; Matos-Perdomo, E.; Medina-Coello, C.; Estévez-Braun, A.; Machín, F. Yeast cytotoxic sensitivity to the antitumour agent $\beta$-lapachone depends mainly on oxidative stress and is largely independent of microtubule- or topoisomerase-mediated DNA damage. Biochem. Pharmacol. 2014, 92, 206-219.

27. PCMODEL 9.2; Serena Software: Bloomington, IN, USA, Copyright 1988e2006; Available online: www. serenasoft.com (accessed on 20 July 2020).

28. Jaguar, Version 7.8; Schrodinger: New York, NY, USA, 2011.

29. Schlegel, B. Estimating the hessian for gradient-type geometry optimizations. Theor. Chim. Acta 1984, 66, 333-340. [CrossRef]

30. Bochevarov, A.D.; Harder, E.; Hughes, T.F.; Greenwood, J.R.; Braden, D.A.; Philipp, D.M.; Rinaldo, D.; Halls, M.D.; Zhang, J.; Friesner, R.A. Jaguar: A high-performance quantum chemistry software program with strengths in life and materials sciences. Int. J. Quantum Chem. 2013, 113, 2110-2142. [CrossRef]

Sample Availability: Samples of the compounds 3a-31, $4 a-41$ and $5 a-51$ are available from the authors. 